\title{
Adjoint Sensitivity of North Pacific Atmospheric River Forecasts
}

\author{
CAROLYn A. REYNOLDS AND JAMES D. DOYLE \\ Marine Meteorology Division, Naval Research Laboratory, Monterey, California \\ F. MARTIN RALPH AND REUBEN DEMIRDJIAN \\ Center for Western Weather and Water Extremes, Scripps Institution of Oceanography, \\ University of California, San Diego, San Diego, California
}

(Manuscript received 4 October 2018, in final form 15 February 2019)

\begin{abstract}
The initial-state sensitivity and optimal perturbation growth for 24- and 36-h forecasts of low-level kinetic energy and precipitation over California during a series of atmospheric river (AR) events that took place in early 2017 are explored using adjoint-based tools from the Coupled Ocean-Atmosphere Mesoscale Prediction System (COAMPS). This time period was part of the record-breaking winter of 2016-17 in which several high-impact ARs made landfall in California. The adjoint sensitivity indicates that both lowlevel winds and precipitation are most sensitive to mid- to lower-tropospheric perturbations in the initial state in and near the ARs. A case study indicates that the optimal moist perturbations occur most typically along the subsaturated edges of the ARs, in a warm conveyor belt region. The sensitivity to moisture is largest, followed by temperature and winds. $\mathrm{A} 1 \mathrm{~g} \mathrm{~kg}^{-1}$ perturbation to moisture may elicit twice as large a response in kinetic energy and precipitation as a $1 \mathrm{~m} \mathrm{~s}^{-1}$ perturbation to the zonal or meridional wind. In an average sense, the sensitivity and related optimal perturbations are very similar for the kinetic energy and precipitation response functions. However, on a case-by-case basis, differences in the sensitivity magnitude and optimal perturbation structures result in substantially different forecast perturbations, suggesting that optimal adaptive observing strategies should be metric dependent. While the nonlinear evolved perturbations are usually smaller (by about $20 \%$, on average) than the expected linear perturbations, the optimal perturbations are still capable of producing rapid nonlinear perturbation growth. The positive correlation between sensitivity magnitude and wind speed forecast error or precipitation forecast differences supports the relevance of adjoint-based calculations for predictability studies.
\end{abstract}

\section{Introduction}

The "water" year spanning 1 October 2016-30 September 2017 brought record or near-record setting rainfall across much of California. The northern Sierra received an average of $94.7 \mathrm{in}$. , breaking the previous record, set in the $1982 / 83$ El Niño year, by more than 6 in., as detailed in a NOAA report. ${ }^{1}$ This report also notes that while $83.6 \%$ of California was in a drought state (with $21 \%$ in an exceptional drought state) at the beginning of the water year, only $8 \%$ of California was in a drought state at the

\footnotetext{
${ }^{1}$ https://www.climate.gov/news-features/featured-images/verywet-2017-water-year-ends-california.
}

Corresponding author: Carolyn A. Reynolds, carolyn.reynolds@ nrlmry.navy.mil end of the water year (and no area of California was in an exceptional drought state). Much of the precipitation occurred during January and the first three weeks of February 2017. The storms during these two months had enormous hydrological impacts, including mudslides and widespread flooding, and were often accompanied by high winds. A description of these storms and their hydrological impacts is given in detail by the NOAA California Nevada River Forecast Center. ${ }^{2}$

Much of the precipitation that fell during the JanuaryFebruary 2017 period was associated with atmospheric rivers (ARs), which are long corridors of strong horizontal moisture vapor transport, and account for more than $90 \%$ of the water vapor transport outside of the tropics (Zhu and Newell 1998; Ralph et al. 2004, 2017, 2018;

\footnotetext{
${ }^{2}$ https://www.cnrfc.noaa.gov/storm_summaries/janfeb2017storms.php.
} 
Gimeno et al. 2014). When the moist air associated with ARs is lifted over coastal mountains, they can be associated with large amounts of precipitation and flooding (Ralph et al. 2006; Dettinger et al. 2011; Lavers et al. 2011; Neiman et al. 2011; Lavers and Villarini 2013; Ramos et al. 2015). Hazards associated with land-falling ARs are not limited to flooding, as they are often accompanied by high winds. Waliser and Guan (2017) find ARs are typically associated with a doubling of near-surface wind speeds compared to all storm conditions. Despite continuing advances in numerical weather prediction (NWP) skill, there are still challenges associated with short-term forecasts of ARs. Lavers et al. (2016a) find that larger forecast uncertainty in integrated vapor transport (IVT) in the NCEP Global Ensemble Forecast System (GEFS) occurs with cyclonic conditions over the North Pacific (associated with more frequent ARs and extreme hydrological events over western North America) than occurs during anticyclonic conditions. Lavers et al. (2016b) find that an extreme forecast index (EFI) based on IVT from the European Centre for Medium-Range Weather Forecasts (ECMWF) ensembles is not as skillful at predicting extreme precipitation events at short lead times as an EFI based directly on precipitation. DeFlorio et al. (2018) find that the percentage of ECMWF ensemble members that correctly capture an AR landfall within $250 \mathrm{~km}$ drops below $75 \%$ within $48 \mathrm{~h}$ (their Fig. 4).

Given these impacts and associated forecasting challenges, ARs have been the subject of field campaigns including CALJET, PACJET, and Calwater (Ralph et al. 2005, 2016) and the 2018 AR reconnaissance program (Ralph 2018). In these field experiments dropsonde are deployed from research aircraft to gather in situ information on the winds, temperature, and moisture within the ARs and in nearby regions of interest (Ralph et al. 2017) for process studies, model verification and validation, and forecast improvement. Lavers et al. (2018) use the 2018 AR reconnaissance dropsondes assimilated into the ECMWF Integrated Forecast System (IFS) to evaluate AR structure representation and determine the primary sources of errors in water vapor flux forecasts. While the AR structure is generally well captured, short-range forecast errors of water vapor fluxes are about $22 \%$ of the mean observed flux. These errors are related to uncertainties in winds (primarily) and moisture near the top of the boundary layer.

Motivated by high socioeconomic impacts coupled with continuing forecast challenges, we examine how short-term forecasts of winds and precipitation over California in January and February 2017 are sensitive to changes in their initial states. For this task we use an adjoint method, which allows for the efficient calculation of how a particular forecast measure (response function) is sensitive to changes in the initial state (Errico 1997). Adjoint and related singular vector techniques have been applied to extratropical cyclones and baroclinic systems in the context of simplified models (e.g., Farrell 1989; Langland et al. 1995), dynamics and predictability studies (e.g., Buizza and Palmer 1995; Gelaro et al. 2000; Reynolds et al. 2001; Kleist and Morgan 2005), forecast error sensitivity (e.g., Rabier et al. 1996), and targeted observations (see review paper by Majumdar 2016). The metric or response function (RF) in previous studies is usually total energy or kinetic energy (KE). Exceptions include the use of convective available potential energy (Stappers and Barkmeijer 2011) and precipitation (Errico et al. 2003; Mahfouf and Bilodeau 2007; Zhou and Cui 2015). As ARs are often associated with high winds and intense precipitation, we consider both KE and precipitation RFs.

This study is motivated in part by Doyle et al. (2014), who use the forecast and adjoint system of the Navy Coupled Ocean-Atmosphere Mesoscale Prediction System (COAMPS; Hodur 1997) to evaluate the sensitivity of a rapidly intensifying Atlantic extratropical cyclone to changes in the initial state. They find that forecasted low-level $\mathrm{KE}$ of the storm is most sensitive to small filaments of moisture within an AR, specifically along the warm front and within the warm conveyor belt (WCB; Carlson 1980; Wernli 1997). The WCB is the region of sloped ascending air in the warm sector of extratropical cyclones and typically flows northward parallel to the cold front, ascending over the warm front. Binder et al. (2016) find a moderate to strong correlation between WCB strength and Northern Hemisphere extratropical cyclone intensification. ARs (or components of ARs) are often associated with strong vapor transport found within WCBs (e.g., Cordeira et al. 2013; Grams and Archambault 2016).

The importance of moisture transport in storm evolution has also been found using other techniques. Schäfler and Harnisch (2015) find that changes to warm conveyor belt inflow introduced through the assimilation of airborne DIAL water vapor data produce significant forecast changes to low-level potential vorticity (PV) production, tropopause height, and jet stream wind speed. Zhang and Meng (2018) use ensemble-based sensitivity analysis (Torn and Hakim 2008, 2009) to identify the key synoptic factors that impact precipitation during a heavy rainfall event in southern China. They find that the forecast skill and uncertainty of rainfall is mainly associated with the characteristics of the low-level jet in regions of strong moisture transport. Other ensemble-based sensitivity analyses using a precipitation metric include Schumacher (2011), Lynch and Schumacher (2014), 
Bednarczyk and Ancell (2015), and Yu and Meng (2016). Varied results in these studies indicate that forecast sensitivity will be very case dependent. In addition, results are sensitive to the choice of metrics for ensemble sensitivity (e.g., Zheng et al. 2013; Chang et al. 2013; Smith and Ancell 2017) and adjoint sensitivity and related singular vector techniques (e.g., Palmer et al. 1998; Errico et al. 2003; Mahfouf and Bilodeau 2007; Doyle et al. 2019, manuscript submitted to Mon. Wea. Rev.).

The purpose of this study is to 1) identify the regions and variables in the initial state that have the greatest potential impact on the 24-36-h forecasts of ARs along the U.S. West Coast and 2) compare sensitivity based on a KE RF to that based on a precipitation RF in a systematic manner. We will use the COAMPS forecast and adjoint system as was used for the Atlantic extratropical cyclone study by Doyle et al. (2014) and will consider both a lower-tropospheric KE RF and an accumulated precipitation RF (Doyle et al. 2019, manuscript submitted to Mon. Wea. Rev.). These findings can provide guidance on where reducing analysis uncertainty may have the biggest impact on forecast error, and where capturing that analysis uncertainty in ensemble design is most important. We will also be able to determine if these key aspects of analysis uncertainty are different for forecasts of winds versus forecasts of precipitation. Section 2 describes the methodology and systems used. Section 3 describes a case study. Section 4 describes the general results based on the 7-week period of high-impact rainfall events over California in January and February 2017. A summary and conclusions is presented in section 5 .

\section{Methodology}

\section{a. Adjoint sensitivity and optimal perturbations}

A detailed description of the adjoint sensitivity methodology employed here is provided in Doyle et al. (2012). The brief description provided here follows closely the description in Reynolds et al. (2016). The sensitivity of a forecast metric $J$ (for model state $\mathbf{x}_{t}$ at time $t$ ) to each component of an earlier model state $\left(\mathbf{x}_{\mathrm{t} 0}\right)$ is represented as

$$
J\left(\mathbf{x}_{t}\right)=J\left[M\left(\mathbf{x}_{\mathrm{t} 0}\right)\right],
$$

where $J$ is the RF and $M$ is the nonlinear model [see Errico (1997) for a detailed description of an adjoint model]. The gradient of $J$ with respect to the initial model state is

$$
\frac{\partial J}{\partial \mathbf{x}_{\mathrm{t} 0}}=\mathbf{M}^{\mathrm{T}} \frac{\partial J}{\partial \mathbf{x}_{t}},
$$

where $\mathbf{M}$ is the tangent linear model of $M$ and superscript $\mathrm{T}$ denotes the transpose. We compute $\partial J / \partial \mathbf{x}_{t}$ through differentiation of $J$ with respect to the model state at time $t ; J$ must be a differentiable and continuous function.

In this paper we make use of adjoint-derived optimal perturbations (Errico and Raeder 1999; Rabier et al. 1996; Oortwijn and Barkmeijer 1995) to examine how fast-growing perturbations impact precipitation and winds over our area of interest. The production of these optimal perturbations follows that used in Doyle et al. (2012) and Doyle et al. (2014). Perturbations to the RF $J$ are expressed as

$$
J^{\prime}=\sum_{j} \frac{\partial J}{\partial x_{j}} x_{j}^{\prime}
$$

where $\partial J / \partial x_{j}$ is the gradient of the RF with respect to the $j$ th initial-state component. The $j$ th component of the perturbation vector $\mathbf{x}^{\prime}$ is optimal when defined such that

$$
x_{j}^{\prime}=\frac{s}{w_{j}} \frac{\partial J}{\partial x_{j}},
$$

for weights $w_{j}$. The method for obtaining weights and scaling parameter $s$ is detailed in Doyle et al. (2014). The scaling $s$ (units of $J^{-1}$ ) is chosen such that the largest perturbation of the water vapor, potential temperature, or zonal wind speed at initial time does not exceed $1 \mathrm{~g} \mathrm{~kg}^{-1}, 1 \mathrm{~K}$, or $1 \mathrm{~m} \mathrm{~s}^{-1}$, respectively. These perturbation magnitudes are chosen such that they are comparable to or smaller than errors assigned to radiosonde and dropsonde observations in the data assimilation system $\left[1 \mathrm{~K}, 1.8 \mathrm{~m} \mathrm{~s}^{-1}\right.$, and $10 \%$ relative humidity at $\left.925 \mathrm{hPa}\left(\sim 1-1.5 \mathrm{~g} \mathrm{~kg}^{-1}\right)\right]$. The optimal perturbations are calculated for potential temperature, the Exner pressure perturbation, mixing ratio, all wind speed components, and microphysical species.

\section{b. Forecast and adjoint system}

The COAMPS forecast and adjoint system is described in detail in Doyle et al. (2012). COAMPS (Hodur 1997) is the nonhydrostatic mesoscale model used for diverse research applications and U.S. Navy operational forecasting. The atmospheric physical parameterizations include a modified Kuo-type convective parameterization (Molinari 1985), modified version of Rutledge and Hobbs (1983) cloud microphysical processes, a surface-layer parameterization (Louis et al. 1982), and prognostic TKE equation (Hodur 1997).

The COAMPS tangent linear and adjoint models are described in detail in Amerault et al. (2008). Identical physical parameterizations are used in the nonlinear, tangent linear, and adjoint models, including ice-phase microphysics. However, long- and shortwave radiative 
processes are ignored in the TLM and adjoint in order to avoid highly nonlinear components of the physics (these processes are included in the nonlinear forecasts). The COAMPS forecast and adjoint systems have been used for tropical cyclone (TC) predictability studies (Doyle et al. 2011, 2012; Reynolds et al. 2016), targeted observing for TCs (Reynolds et al. 2010), predictability studies of severe extratropical TCs (Doyle et al. 2014), and to support the DEEPWAVE (Fritts et al. 2016), NAWDEX (Schäfler et al. 2018), and 2018 ARs Reconnaissance (Ralph 2018) field projects.

\section{c. Experimental design}

COAMPS forecasts are run out to $24 \mathrm{~h}$ and $36 \mathrm{~h}$ every $12 \mathrm{~h}$ for the period including the intensive California rainfall events in early 2017. The COAMPS forecasts are run starting from initial conditions based on the NOAA Global Forecast System (GFS) analyses every 0000 and 1200 UTC, starting at 0000 UTC 1 January-1200 UTC 19 February 2017. The horizontal resolution is approximately $36 \mathrm{~km}$ and the domain extends to an altitude of $30 \mathrm{~km}$ with 40 vertical levels. COAMPS is run in an uncoupled mode with SSTs taken from the Navy Coupled Ocean Data Assimilation (NCODA) system 3D-Var analysis that remain fixed through the forecast integration. The choice to run COAMPS in uncoupled mode with fixed SSTs mimics the setup of most current operational regional forecast systems. However, operational centers such as ECMWF, Met Office, and Environment Canada are finding benefits in ocean coupling for lead times as short as a few days (e.g., Smith et al. 2018). In future studies, we plan to examine both the COAMPS adjoint sensitivity of AR forecasts to changes in the fixed SST and to examine the impact of ocean coupling on AR forecasts using the COAMPS interactive ocean capability. The domain covers most of the central and eastern North Pacific and western third of the contiguous United States, with lateral boundaries at $8^{\circ} \mathrm{N}$, $57^{\circ} \mathrm{N}, 173^{\circ} \mathrm{E}$, and $103^{\circ} \mathrm{W}$. Lateral boundary conditions are provided by GFS forecasts. The RF box is centered over the central-southern U.S. West Coast and adjoining ocean region with lateral boundaries at $33^{\circ} \mathrm{N}, 40.5^{\circ} \mathrm{N}$, $125^{\circ} \mathrm{W}$, and $117.5^{\circ} \mathrm{W}$, and contains most of California, including the coastal ranges and Sierra Nevada (denoted by the black rectangle in Fig. 1).

As noted in the introduction, ARs are often accompanied by strong, sometimes damaging winds as well as intense precipitation. As such we are interested in investigating the differences between adjoint sensitivity and related optimal perturbations for metrics that reflect both wind and rainfall. For the purpose of identifying the sensitivity of the forecasted low-level wind speeds to changes in the initial state, we use a KE RF.
The KE RF is defined as the KE in the RF box between the surface and $1000 \mathrm{~m}$ at the forecast final time (either 24 or $36 \mathrm{~h}$ ). Given that we are interested in the sensitivity of the forecast to changes in the initial state, the optimization time (i.e., the forecast range over which the adjoint calculation is performed) is equivalent to the forecast length. To identify the sensitivity of forecasted rainfall to changes in the initial state, we use a precipitation (PR) RF. The precipitation response function differs from that of other typical response functions in that $J$ is a forecast metric that is accumulated over time, rather than instantaneously. $J$ can be defined as precipitation accumulated over any specified forecast time interval. Here, the PR RF is defined as the total accumulated precipitation within the RF box between $21 \mathrm{~h}$ and $24 \mathrm{~h}$ in the $24-\mathrm{h}$ forecasts. The PR RF only provides meaningful results when the forecast has some precipitation in the RF box over the later part of the forecast. In the 36 -h forecast, a longer $(6 \mathrm{~h})$ period of precipitation accumulation (between 30 and $36 \mathrm{~h}$ ) is chosen to compensate for the fact that precipitation timing errors are more likely in 36-h forecasts than $24-\mathrm{h}$ forecasts.

In our comparisons, we are excluding the COAMPS forecasts when precipitation does not fall in the RF box. While the KE RF cases are not subject to the same constraint, we exclude the same dry cases from both the KE and PR RF experiments so as to make a clean comparison between the two. The KE RF 24- and 36-h experiments are denoted as KE24 and KE36 respectively. The PR RF cases are likewise denoted as PR24 and PR36. Table 1 describes these experiments and also gives a list of the "dry" dates that are excluded from the set. For this particular set up, given the fairly large RF box and short forecast lead time, COAMPS has at least some rainfall for all the significant rain events. Most of the excluded cases occur during relatively dry breaks between rain events as noted in the California Nevada River Forecast Center's analysis. ${ }^{3}$ The PR RF does work for all of the most significant rain events (e.g., dates with over 2 in. of 24 -h precipitation in the northern Sierra ending at 1200 UTC 4, 8, 9, 11, and 19 January, and 7, 9, 10, and 21 February). Nevertheless it should be kept in mind that the PR RF is limited by the fact that it will not work in cases where the nonlinear forecast completely misses a rain event, which is more likely at longer forecast lead times and for smaller RF regions. An alternative may be to consider an RF related to precipitation, such as IVT. When comparing the two RFs, we use the adjoint sensitivity-derived optimal

\footnotetext{
${ }^{3}$ https://www.cnrfc.noaa.gov/storm_summaries/janfeb2017storms.php.
} 
a) OOh KE24 700 WVAP; IVT; SLP; q'

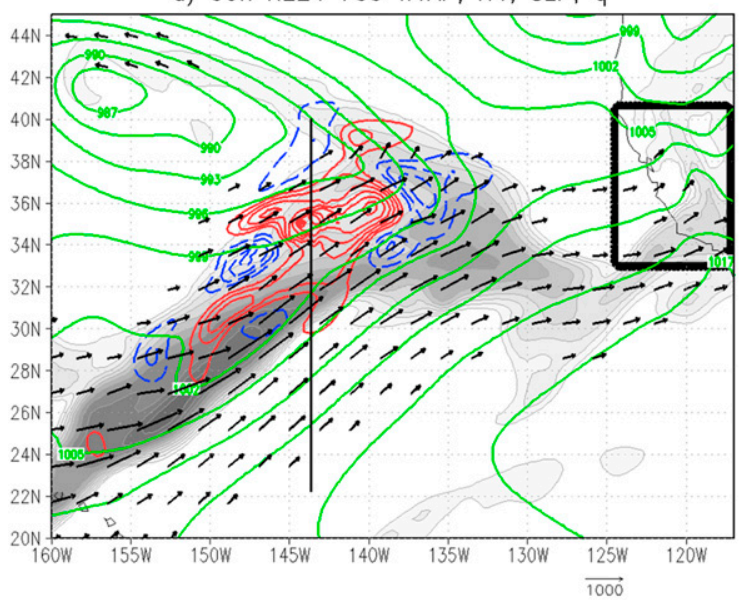

c) 00h PR24 700 WVAP; IVT; SLP; q'

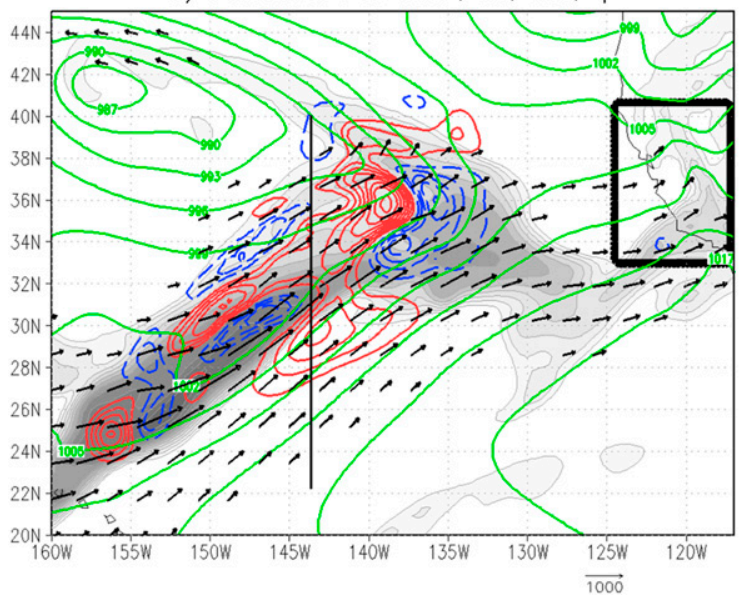

b) 00 h KE24 700 WS; Winds; SLP; WS'

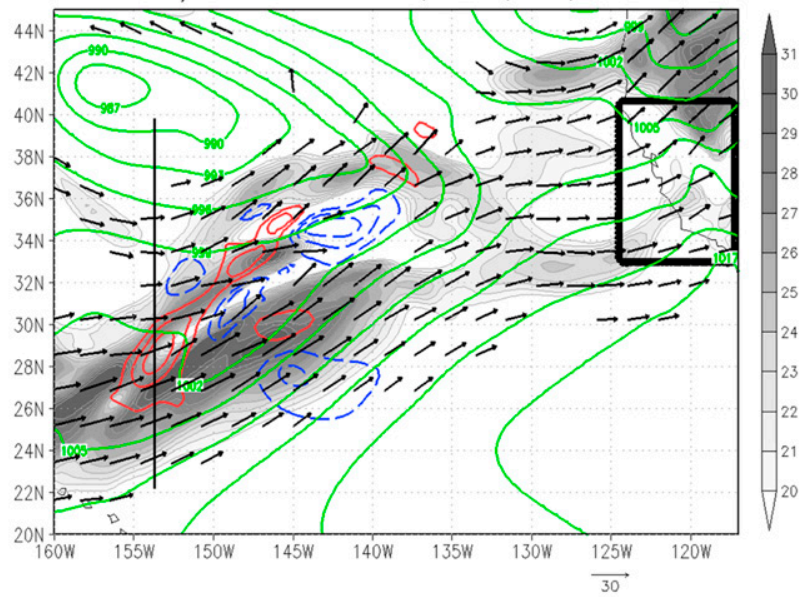

d) OOh PR24 700 WS; Winds; SLP; WS'

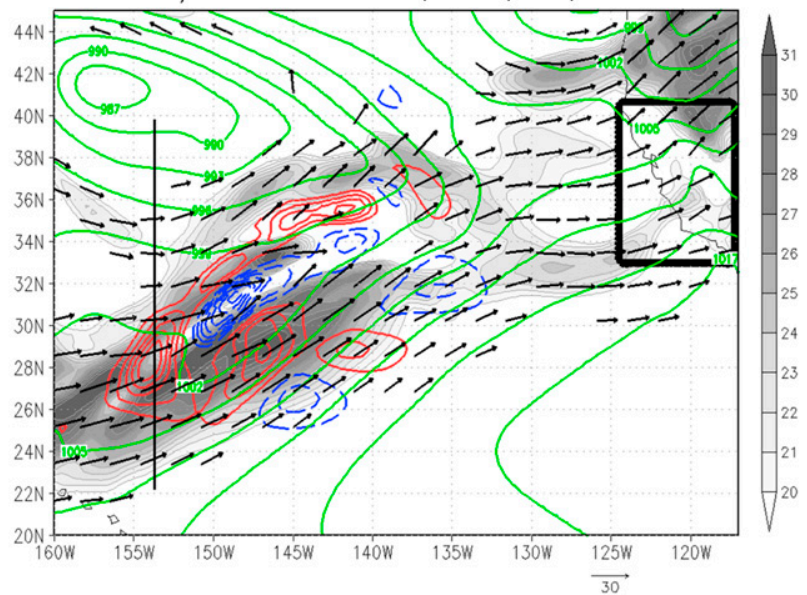

FIG. 1. Initial-time optimal perturbations and analysis fields for (a),(b) KE24 and (c),(d) PR24 for 1200 UTC 6 Feb 2017. (a),(c) Control analyzed 700-hPa water vapor ( $\mathrm{g} \mathrm{kg}^{-1}$, gray shading), IVT (black vectors, greater than $300 \mathrm{~kg} \mathrm{~m}^{-1} \mathrm{~s}^{-1}$ ), SLP (green contours), and 700-hPa water vapor optimal perturbation [contour interval (ci) $=0.05 \mathrm{~g} \mathrm{~kg}^{-1}$, positive values red, negative values blue]. (b), (d) Analyzed 700-hPa wind speed ( $\mathrm{m} \mathrm{s}^{-1}$, gray shading), wind vectors (black vectors, greater than $12 \mathrm{~m} \mathrm{~s}^{-1}$ ), SLP (green contours), and 700-hPa optimal perturbation wind speed (wind speed of the perturbed analysis - wind speed of the control analysis, ci $=0.01 \mathrm{~m} \mathrm{~s}^{-1}$, positive values red, negative values blue). Straight black lines correspond to cross-sectional locations shown in Fig. 2.

perturbations, as the unit difference between the actual sensitivity fields makes quantitative comparison difficult. The spatial patterns of the sensitivity and optimal perturbations are the same.

As described in section 2a, an optimal perturbation is constructed from each sensitivity pattern and propagated forward in time using the COAMPS tangent linear model. This optimal perturbation is also added to the initial conditions and a subsequent "nonlinearperturbed" COAMPS forecast is produced. The nonlinear perturbation is defined as the difference between the control forecast and this perturbed forecast. We compare the nonlinear and linear perturbations to assess the appropriateness of the tangent linear assumption. From previous studies (Reynolds and Rosmond 2003;
Ancell and Mass 2006) it is shown that smaller scales and simulations at finer resolutions become nonlinear faster than larger scales and simulations at coarser resolutions. The choice of a $36-\mathrm{km}$ resolution provides a good representation of the ARs and synoptic-to-mesoscale variability while allowing for a reasonably good match between nonlinear and linear perturbation growth (as discussed in section 4). It is also of comparable resolution to that used in Doyle et al. (2012), Jung et al. (2013), and Reynolds et al. (2016), and finer than the $O(100) \mathrm{km}$ resolution or larger used in several previous studies (e.g., Peng and Reynolds 2006; Kim and Jung 2009; Lang et al. 2012). However, it does not capture finescale details in precipitation related to topography, and we plan further studies using nested high-resolution 
TABLE 1. Description of the sensitivity experiments. Forecasts and adjoint sensitivities are run every 0000 and 1200 UTC from 0000 UTC 1 Jan 2017 to 1200 UTC 19 Feb 2017 with the exception of cases excluded because of no rain in the COAMPS forecast in the response function domain.

\begin{tabular}{|c|c|c|c|}
\hline Name & Response function & Optimization time & Cases excluded \\
\hline KE24 & 24-h forecast kinetic energy below $1000 \mathrm{~m}$ & $24 \mathrm{~h}$ & 1200 UTC 5 Jan, 1200 UTC 15 \\
\hline PR24 & $\begin{array}{l}\text { 21-24-h forecast accumulated } \\
\text { precipitation }\end{array}$ & & $\begin{array}{l}\text { Jan-1200 UTC } 16 \text { Jan, } 1200 \text { UTC } \\
24 \text { Jan, } 0000 \text { UTC } 26 \text { Jan, } 1200 \text { UTC } \\
27 \text { Jan-1200 UTC } 31 \text { Jan, } 1200 \text { UTC } \\
4 \text { Feb, } 0000 \text { UTC } 12 \text { Feb-1200 UTC } \\
14 \text { Feb, } 0000 \text { UTC } 18 \text { Feb }\end{array}$ \\
\hline KE36 & 36-h forecast kinetic energy below $1000 \mathrm{~m}$ & $36 \mathrm{~h}$ & 1200 UTC 5 Jan, 0000 UTC 12 Jan, \\
\hline PR36 & $\begin{array}{l}\text { 30-36-h forecast accumulated } \\
\text { precipitation }\end{array}$ & & $\begin{array}{l}0000 \text { UTC } 15 \text { Jan-1200 UTC } 16 \text { Jan, } \\
1200 \text { UTC } 23 \text { Jan, 0000-1200 UTC } \\
25 \text { Jan, 0000 UTC } 27 \text { Jan-0000 UTC } \\
30 \text { Jan, 0000 UTC } 31 \text { Jan, 0000 UTC } \\
10 \text { Feb, 0000 UTC } 11 \text { Feb-1200 UTC } \\
13 \text { Feb, } 1200 \text { UTC } 14 \text { Feb-0000 UTC } \\
15 \text { Feb, 0000 UTC } 16 \text { Feb }\end{array}$ \\
\hline
\end{tabular}

adjoint simulations to look at (e.g., flooding in specific hydrological drainage basins).

\section{Case study}

While our primary purpose is to describe the general characteristics of the KE and PR sensitivities, we start with a case study to provide context for the general results that follow. For the case study we have chosen a date during a prolonged period of heavy rainfall over California in early February 2017. It was during this period that the Oroville Dam crisis occurred. The Oroville Dam is on the Feather River in Northern California, located at $39.54^{\circ} \mathrm{N}, 121.49^{\circ} \mathrm{W}$. A timeline of events is provided by California Department of Water Resources report. ${ }^{4}$ Between 6 and 10 February 2017, $330 \mathrm{~mm}$ of rain fell on the Feather River basin. The main spillway was damaged on 7 February, leading to the use of the emergency spillway, the rapid erosion and potential collapse of which led to the evacuation of 188000 people on 12 February. Fortunately the weir associated with the emergency spillway did not collapse.

We consider the sensitivity-based optimal perturbations for KE24 and PR24 initialized at 1200 UTC 6 February 2017. Figures 1a and 1c show the initial optimal perturbations (with structures based on the adjoint sensitivity) for the 700-hPa water vapor (red and blue contours) superimposed upon the analyzed 700-hPa water vapor (gray shading), IVT (black vectors), and SLP (green contours) for KE24 (Fig. 1a) and PR24 (Fig. 1c). Figures 1b and 1d show the speed of

\footnotetext{
${ }^{4}$ water.ca.gov/LegacyFiles/Oroville-spillway/pdf/2017/Lake \% 20Oroville\%20events\%20timeline.pdf.
}

the 700-hPa wind optimal perturbations (red and blue contours), superimposed on the analyzed $700-\mathrm{hPa}$ wind speed (gray shading), wind vectors (black vectors) and SLP (green contours). The perturbations are very small by construction, with max water vapor perturbations less than $0.44 \mathrm{~g} \mathrm{~kg}^{-1}$ and max wind speed perturbations less than $0.1 \mathrm{~m} \mathrm{~s}^{-1}$ (the maximum perturbations within the full domain are less than $1 \mathrm{~g} \mathrm{~kg}^{-1}, 1 \mathrm{~m} \mathrm{~s}^{-1}$, and $1 \mathrm{~K}$ for moisture, winds, and temperature, respectively). The water vapor perturbations are generally within or on the northern flank of the AR along the cold front and WCB region. The PR24 perturbations extend farther to the SW than the KE perturbations. This is consistent with Doyle et al. (2014) who show that the rapidly intensifying Atlantic extratropical cyclone Xynthia is most sensitive to finescale filament structures in the low-level moisture of an AR associated with the WCB. The wind speed perturbations occur in similar locations, within and to the north of the main wind speed maximum, although the PR24 pattern has considerable amplitude to the south of this feature as well. The largest wind speed perturbations (and largest sensitivity) occur in the vicinity of the WCB inflow region. There are also significant moisture perturbations in the WCB inflow region, but the largest moisture perturbations (and moisture sensitivity) are in the ascent region of the WCB near the junction of the warm and cold fronts. The wind perturbations act to enhance the convergence associated with the cold frontal wave in the vicinity of $31^{\circ} \mathrm{N}, 148^{\circ} \mathrm{W}$.

Meridionally oriented vertical cross sections are shown at $144^{\circ} \mathrm{W}$ (the longitude with the largest vertically integrated absolute value of moisture sensitivity for KE24) for the water vapor sensitivity (red and blue contours) superimposed on the relative humidity (gray shading), potential temperature (green contours) and 
a) OOh KE24 144W RH; Theta; WV; q'

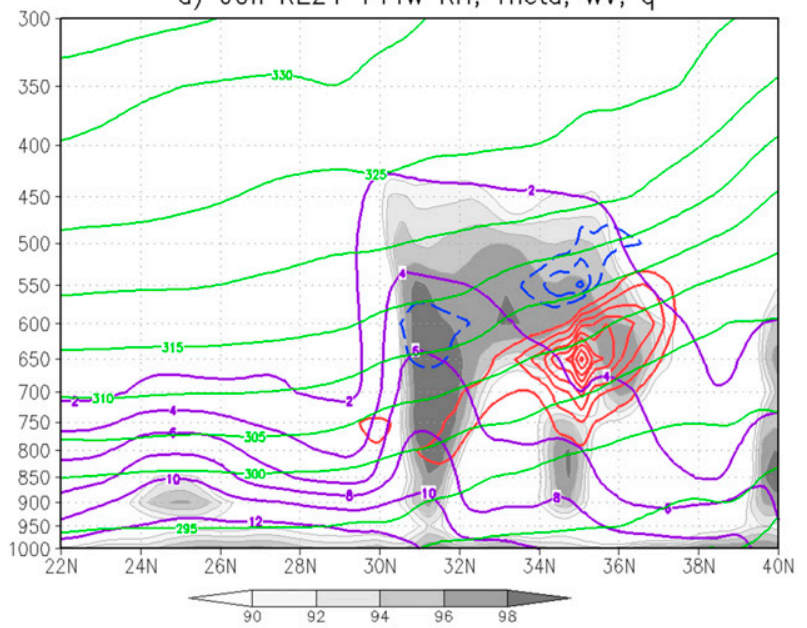

c) OOh PR24 144W RH; Theta; WV; q'

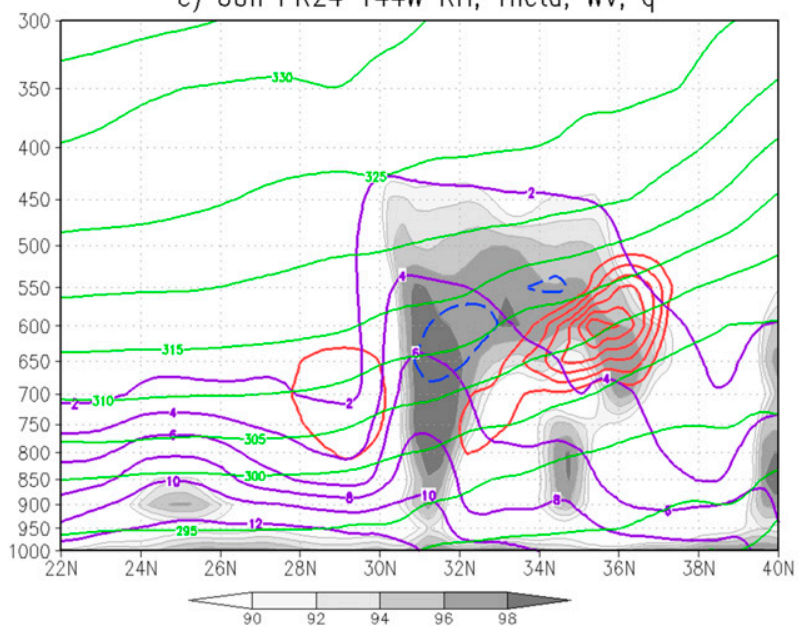

b) 00h KE24 154W PV; Theta; WV; PV'

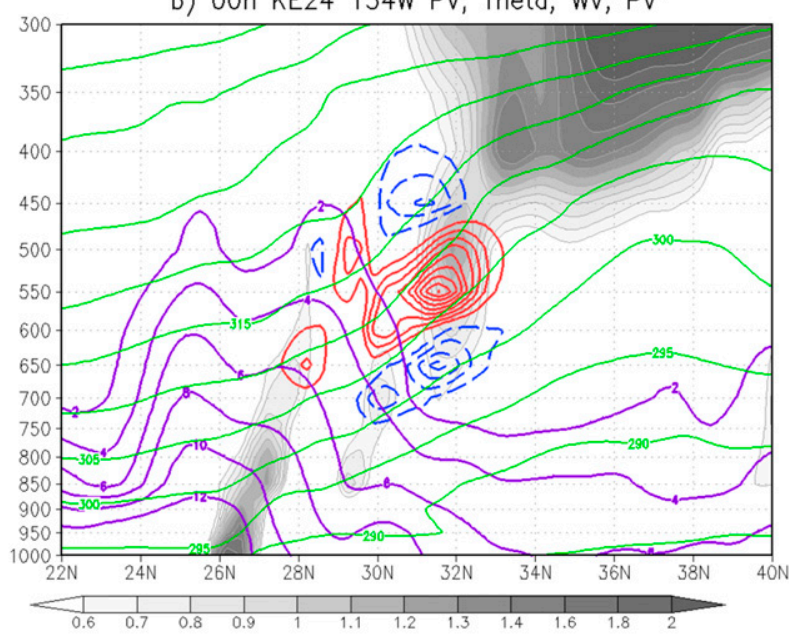

d) 00h PR24 154W PV; Theta; WV; PV'

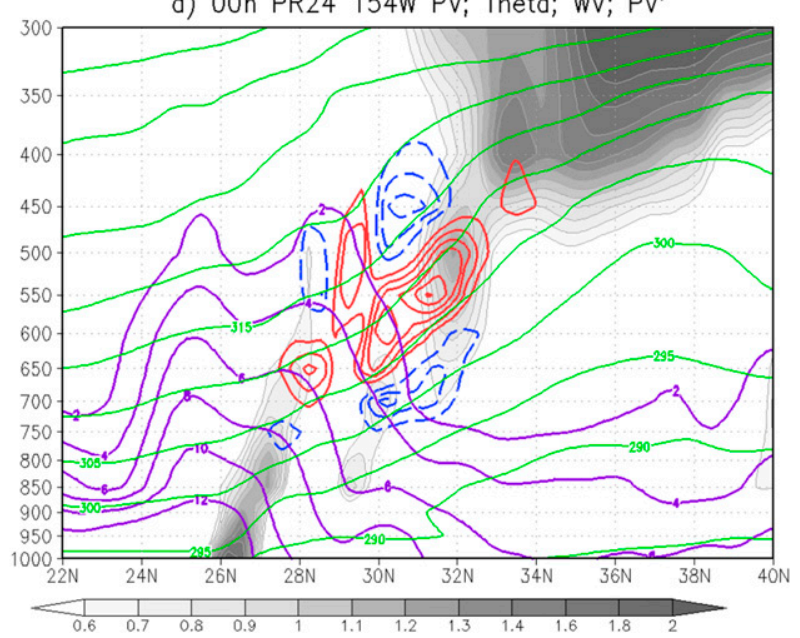

FIG. 2. Vertical cross sections as a function of latitude for initial-time optimal perturbations and analysis fields for (a),(b) KE24 and (c),(d) PR24 for 1200 UTC 6 Feb 2017. (a),(c) Control analyzed relative humidity (gray shading), water vapor (g kg ${ }^{-1}$, purple contours), potential temperature (K, green contours), and water vapor optimal perturbation (ci $=0.1 \mathrm{~g} \mathrm{~kg}^{-1}$, positive values red, negative values blue) at $144^{\circ} \mathrm{W}$. (b),(d) Analyzed potential vorticity [gray shading, PVU $\left(10^{-6} \mathrm{~K} \mathrm{~m}^{2} \mathrm{~kg}^{-1} \mathrm{~s}^{-1}\right)$ values shown in key], water vapor (g kg ${ }^{-1}$, purple contours), potential temperature (K, green contours), and optimal perturbation potential vorticity (ci $=0.007$ PVU, positive values red, negative values blue) at $154^{\circ} \mathrm{W}$.

water vapor (purple contours) in Figs. 2a,c. Both KE24 (Fig. 2a) and PR24 (Fig. 2c) indicate sensitivity near the top and to the north of the AR as denoted by the analyzed water vapor as well as vapor transport (not shown). The moisture optimal perturbations tend not to occur in regions where either the water vapor or relative humidity is greatest, but rather where the relative humidity gradient is large, in effect filling in some of the relatively drier regions. Cross sections of temperature and vertical velocity optimal perturbations (not shown) look very similar to the moisture optimal perturbation cross sections. The KE24 and PR24 perturbations are broadly similar but differ in detail, with a larger positive moisture perturbation to the south of the AR in the PR24 case than in the KE24 case.

$\mathrm{PV}$ cross sections at $154^{\circ} \mathrm{W}$ (Figs. $2 \mathrm{~b}, \mathrm{~d}$, taken where the vertical integral of the absolute value of the wind sensitivity is a maximum) show that the PV perturbations (red and blue contours) occur over and in between the relatively large values of PV (gray shading) extending down from the upper troposphere to the north, and the strip of high PV in the lower troposphere to the south. As with the moisture perturbations, the PV perturbations occur on the northern upper flank of the AR within the cold front and WCB region. This is again similar to the sensitivity results in Doyle et al. (2014) 
a) 12 h KE24 700 WVAP; IVT; SLP; q'

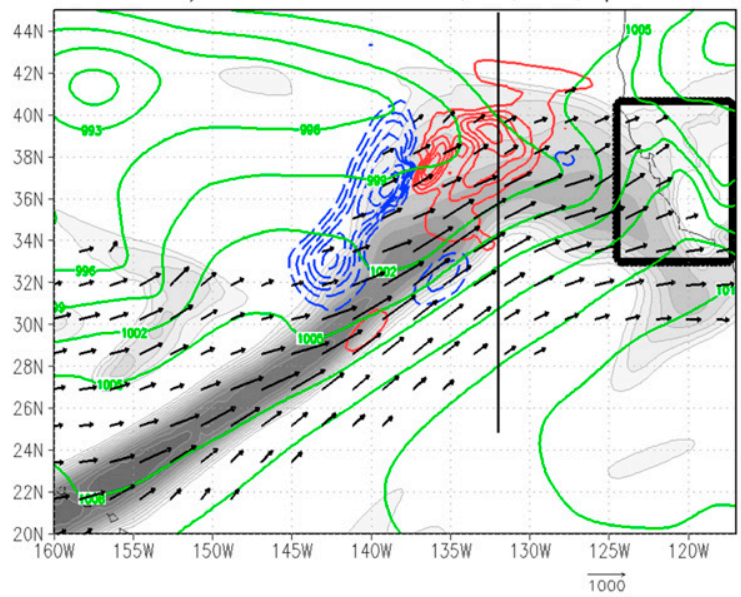

c) $12 \mathrm{~h}$ PR24 700 WVAP; IVT; SLP; q'

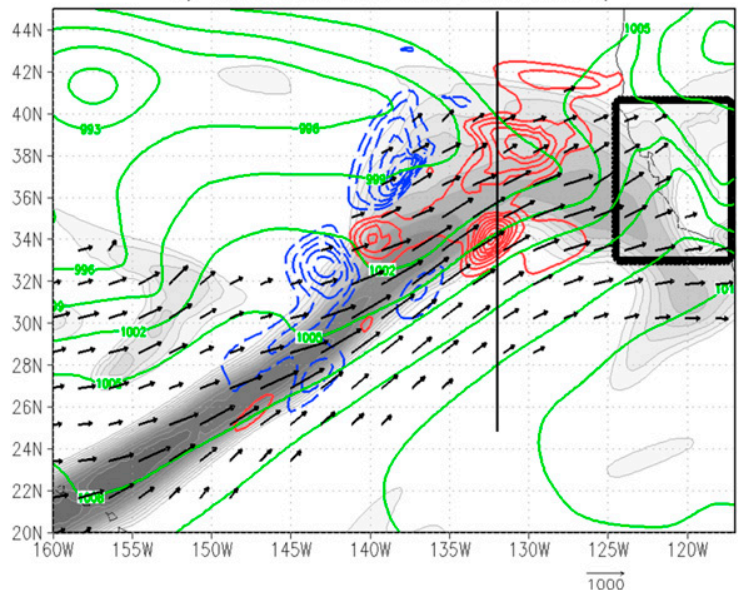

b) $12 \mathrm{~h}$ KE24 700 WS; Winds; SLP; WS'

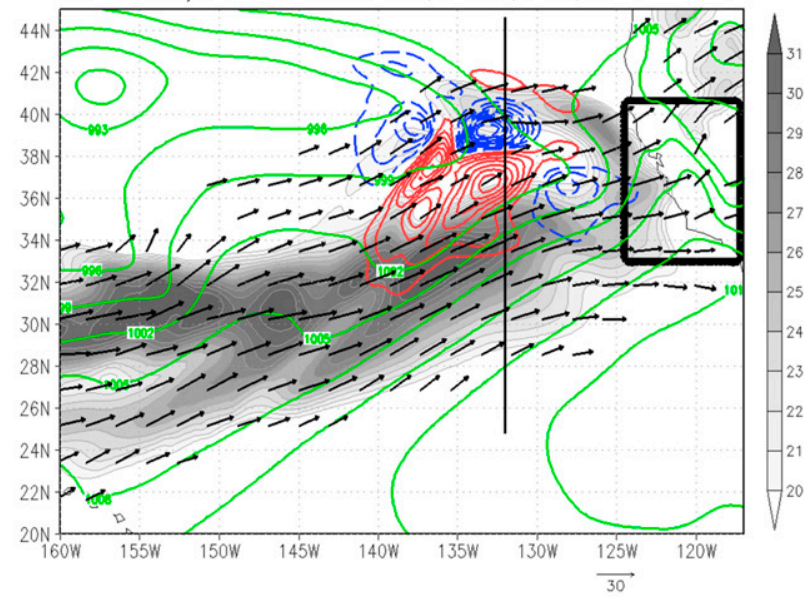

d) 12h PR24 700 WS; Winds; SLP; WS'

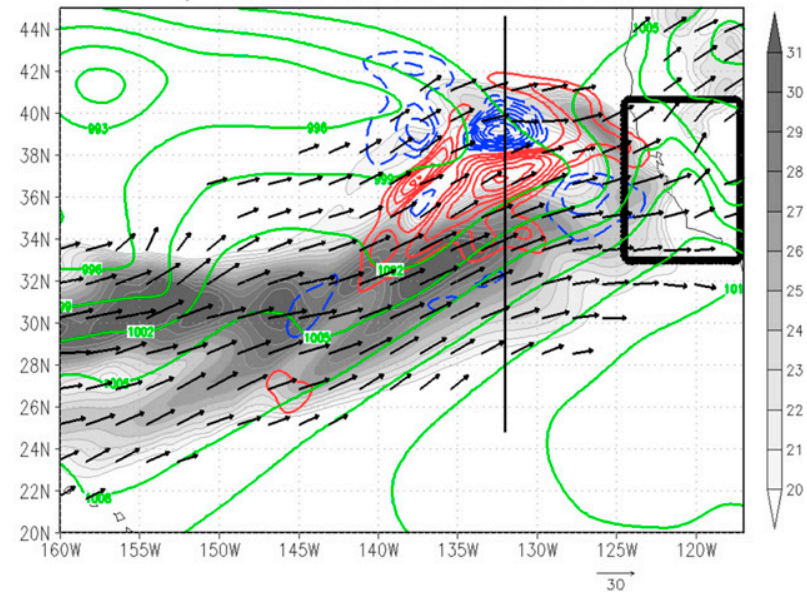

FIG. 3. 12-h evolved optimal perturbations and 12-h forecast fields for (a),(b) KE24 and (c),(d) PR24 valid at 0000 UTC 7 Feb 2017. (a),(c) Control analyzed 700-hPa water vapor ( $\mathrm{g} \mathrm{kg}^{-1}$, gray shading), IVT (black vectors, greater than $300 \mathrm{~kg} \mathrm{~m}^{-1} \mathrm{~s}^{-1}$ ), SLP (green contours), and 700-hPa water vapor optimal perturbation ( $\mathrm{ci}=0.1 \mathrm{~g} \mathrm{~kg}^{-1}$, positive values red, negative values blue). (b),(d) Analyzed 700-hPa wind speed ( $\mathrm{m} \mathrm{s}^{-1}$, gray shading), wind vectors (black vectors, greater than $12 \mathrm{~m} \mathrm{~s}^{-1}$ ), SLP (green contours), and 700-hPa optimal perturbation wind speed (wind speed of the perturbed forecast - wind speed of the control forecast, ci $=0.01 \mathrm{~ms}^{-1}$, positive values red, negative values blue). Straight black lines correspond to cross-sectional locations shown in Fig. 5.

indicating that enhancing and connecting lower- and upper-tropospheric PV anomalies will strengthen the cyclone. The tripole PV perturbation pattern sloping upward along the temperature contours resembles the schematic cold front cross section in, for example, Chagnon et al. (2013, their Fig. 11). Temperature optimal perturbations (not shown) confirm positive temperature perturbations above and negative temperature perturbations below the central PV maximum expected from this paradigm. Lackmann (2002) finds that lowertropospheric PV maxima associated with a cold-front contribute significantly to low-level jet strength in the cyclone warm sector. Our results are consistent with Lackmann (2002) in that strengthening the PV maxima through vertical alignment and diabatic heating will strengthen the low-level jet and associated moisture transport.

Figure 3 is similar to Fig. 1 and shows 12-h linearly evolved optimal perturbations superimposed on the 12-h control forecast fields. Note the change in perturbation contour intervals between Figs. 1 and 3, reflecting substantial perturbation growth in the wind field. Wind and moisture perturbations are concentrated near the intersection of the $\mathrm{AR} /$ cold front and warm front, with moisture perturbations extending southward into the frontal wave at about $32^{\circ} \mathrm{N}, 143^{\circ} \mathrm{W}$. There are differences between the two cases, most notably the moisture perturbations maximum at $34^{\circ} \mathrm{N}, 132^{\circ} \mathrm{W}$ in the $\mathrm{PR} 24$ case (Fig. 3c) missing from the KE24 case (Fig. 3a). Figure 4 shows the $925-\mathrm{hPa}$ control forecast potential temperature 
a) $12 \mathrm{~h} \mathrm{KE24} 925$ Theta; 925 t'; 500 Q-Vector DIV

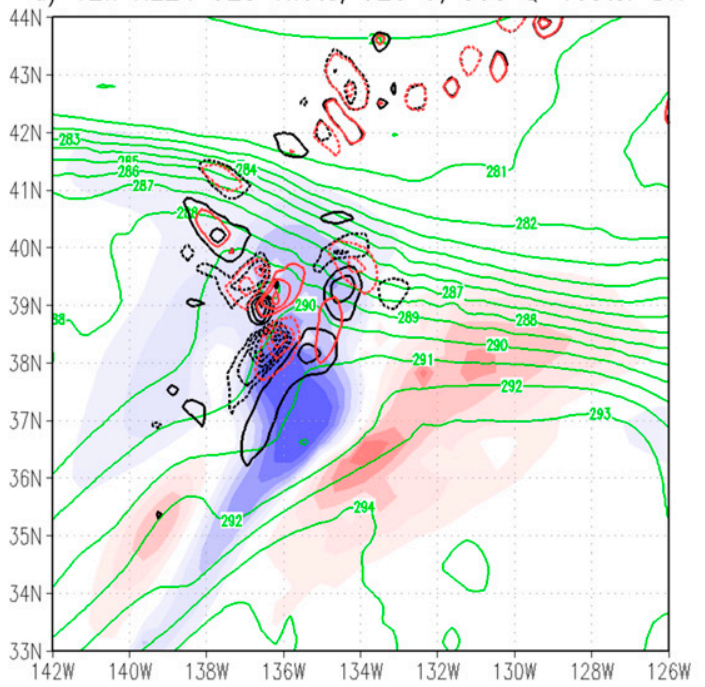

b) $12 \mathrm{~h}$ PR24 925 Theta; $925 \mathrm{t}$; 500 Q-Vector DIV
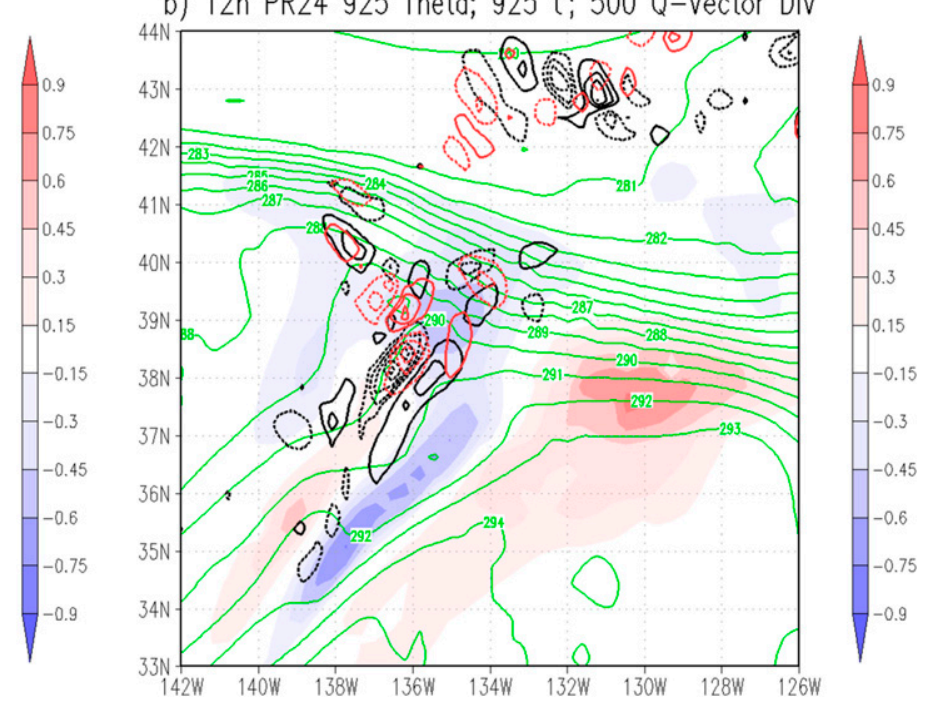

FIG. 4. 12-h evolved optimal perturbations and 12-h forecast fields for (a) KE24 and (b) PR24 valid at 0000 UTC 7 Feb 2017. Fields shown are $925-\mathrm{hPa}$ potential temperature (green contour, $\mathrm{K}$ ), 925-hPa optimal perturbation temperature (K, shading), 500-hPa Q-vector divergence for the control forecast (red contours), and perturbed forecast (black contours), ci $=1 \times 10^{-14} \mathrm{~K} \mathrm{~m}^{-2} \mathrm{~s}^{-1}$, negative values dashed, zero contour omitted.

along with the $925-\mathrm{hPa}$ temperature and $500-\mathrm{hPa} \mathbf{Q}$-vector divergence for both the control and perturbed 12-h forecasts. Q-vector (Hoskins and Pedder 1980) divergence (convergence) is associated with quasigeostrophically forced descent (ascent). The optimal perturbations have evolved to strengthen the temperature gradient along the cold front, more markedly for KE24 (Fig. 4a) than for PR24 (Fig. 4b). Both KE24 and PR24 perturbation runs have much stronger $\mathbf{Q}$-vector divergence and implied quasigeostrophically forced vertical motion (black contours) as compared to the control forecast (red contours), with the largest $\mathbf{Q}$-vector changes indicating increased ascent along the cold front. This first-order change to the quasigeostrophic forcing was also found for dry singular vectors in Reynolds et al. (2001), and suggest a mechanism through which vertically confined initial perturbations may influence lower and upper altitudes.

Cross sections taken at $132^{\circ} \mathrm{W}$ (Fig. 5) show that the optimal perturbations have increased the wind speed in the lower troposphere in the AR between $36^{\circ}$ and $38^{\circ} \mathrm{N}$ by over $4 \mathrm{~m} \mathrm{~s}^{-1}$ (Figs. 4b,d). Substantial positive moisture perturbations now extend toward the surface (Figs. 4 a,c), whereas at initial time the perturbations were mostly confined to between 700 and $500 \mathrm{hPa}$. The increase in moisture and wind speed between $36^{\circ}$ and $38^{\circ} \mathrm{N}$ results in enhanced vapor transport in and on the northern side of the AR. As at initial time, the perturbations act to enhance moisture in subsaturated regions. However, only PR24 has enhanced water vapor on the southern flank of the AR (Fig. 5c), which is somewhat remote from the dynamically active regions to the north and west. The perturbation features common to both KE24 and PR24 in the dynamically active regions on the northern side of the front are constructed to increase both wind speed and precipitation, while the feature unique to PR24 is not designed to increase wind speed, but will increase precipitation by enhancing IVT through moistening.

The resulting linear perturbations at final time (Fig. 6) show how the KE24 and PR24 perturbations enhance the wind speeds and 21- to 24-h accumulated precipitation fields. The $850-\mathrm{hPa}$ wind speed and wind speed linear perturbations in Figs. 6c,e show that PR24 and especially KE24 perturbations enhance the wind speed above the control simulation substantially, especially on the California coast north of San Francisco. The maximum wind speed linear perturbation is $19 \mathrm{~m} \mathrm{~s}^{-1}$ in the KE24 case, and $11 \mathrm{~m} \mathrm{~s}^{-1}$ in the PR24 case, while the maximum wind speed increases from $27.8 \mathrm{~m} \mathrm{~s}^{-1}$ in the control case to $39.3 \mathrm{~m} \mathrm{~s}^{-1}$ in the KE24 case and $33.2 \mathrm{~m} \mathrm{~s}^{-1}$ in the PR24 case. Comparison of the blue (control) and green (perturbed) wind vectors show that the greatest change to the winds is in terms of magnitude, but there is some directional changes as well, which, as demonstrated in Hecht and Cordeira (2017), can have a substantial impact on accumulated precipitation associated with land-falling ARs. Both KE24 and PR24 enhance precipitation over the coastal ranges (Figs. 6d,f) north of San Francisco (by over $12.5 \mathrm{~mm}$ in the KE24 case, and over $10 \mathrm{~mm}$ in the PR24 case), consistent with an increase in orographically 
a) $12 \mathrm{~h} \mathrm{KE24} 132 \mathrm{~W}$ RH; Theta; WV, q'

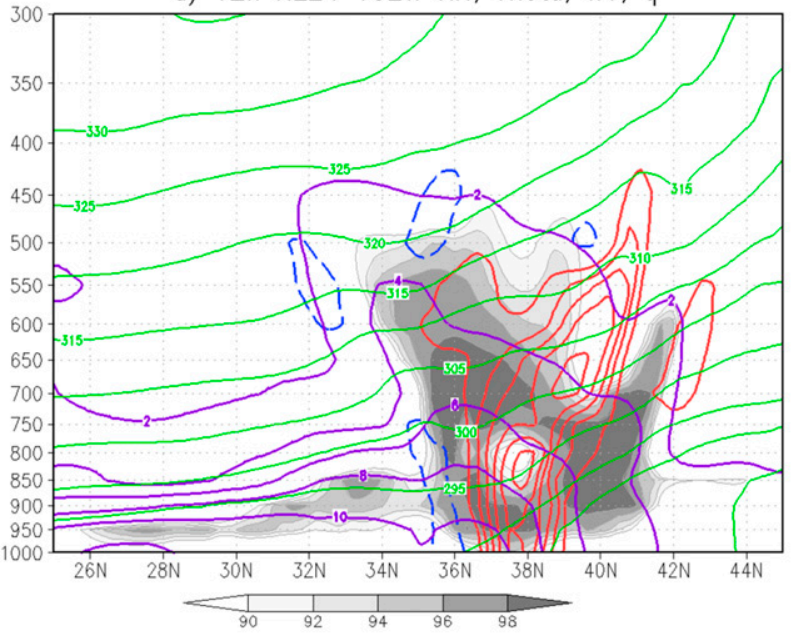

c) $12 \mathrm{~h}$ PR24 132W RH; Theta; WV, q'

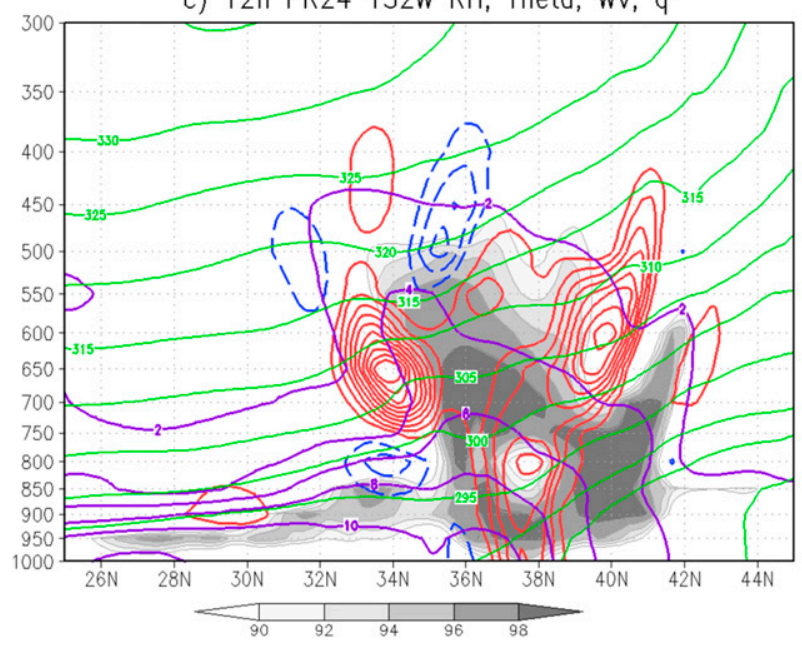

b) $12 \mathrm{~h}$ KE24 $132 \mathrm{~W}$ WS; Theta; WV; WS'

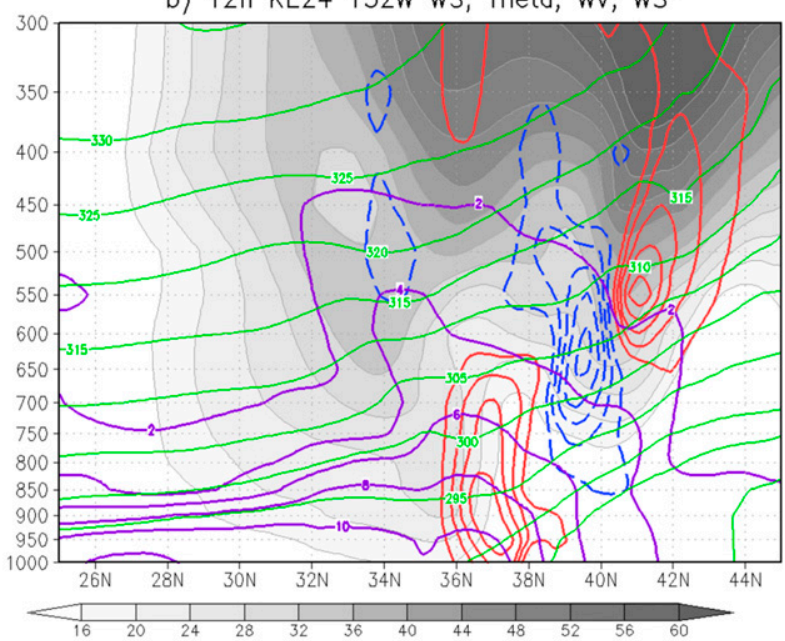

d) $12 \mathrm{~h}$ PR24 132W WS; Theta; WV; WS'

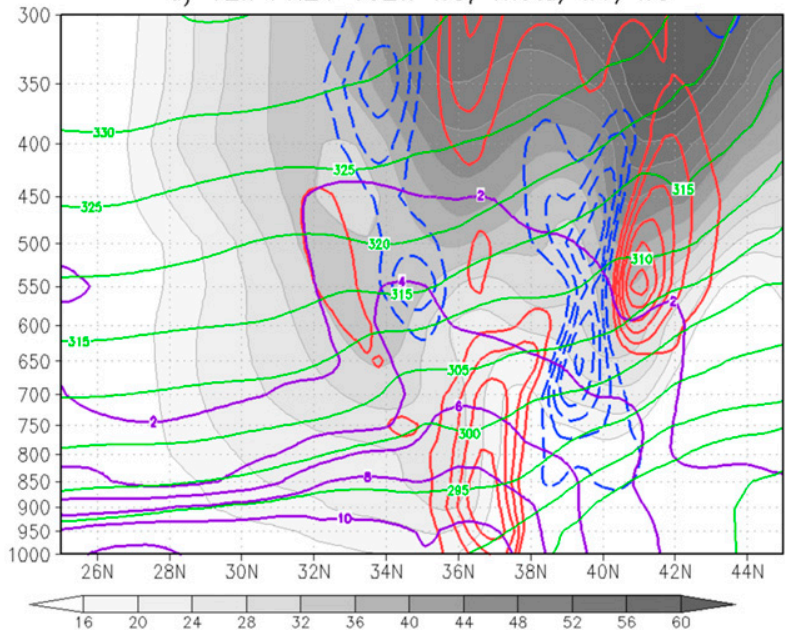

FIG. 5. Vertical cross sections at $132^{\circ} \mathrm{W}$ as a function of latitude for 12 -h evolved optimal perturbations and 12 -h forecast fields for (a),(b) KE24 and (c),(d) PR24 valid at 0000 UTC 7 Feb 2017. (a),(c) Control analyzed relative humidity (gray shading), water vapor ( $\mathrm{g} \mathrm{kg}^{-1}$, purple contours), potential temperature (K, green contours), and water vapor optimal perturbation $\left(\mathrm{ci}=0.1 \mathrm{~g} \mathrm{~kg}^{-1}\right.$, positive values red, negative values blue). (b),(d) Analyzed wind speed (gray shading, $\mathrm{m} \mathrm{s}^{-1}$, values shown in key), water vapor ( $\mathrm{g} \mathrm{kg}^{-1}$, purple contours), potential temperature (K, green contours), and optimal perturbation wind speed (wind speed of the perturbed forecast - wind speed of the control forecast, $\mathrm{ci}=0.01 \mathrm{~m} \mathrm{~s}^{-1}$, positive values red, negative values blue).

enhanced precipitation in this region of stronger onshore flow. However, both the magnitude and extent of the precipitation increase over the Sierra Nevada is considerably larger in the PR24 case than in the KE24 case. In the northern Sierra Nevada, the precipitation is increased by $50 \%$ (from 20 to $30 \mathrm{~mm}$ ) in the PR24 case (Fig. 6f). The nonlinear perturbations (not shown) are $22 \%-25 \%$ smaller than the linear perturbations for the precipitation and $42 \%-42 \%$ smaller than the linear perturbations for the max wind speed. We consider the match between linear and nonlinear perturbations more generally in section 4 . While we have focused on low-level winds and precipitation, the perturbation impacts are felt throughout the troposphere. Examination of perturbation PV at $200 \mathrm{hPa}$ (not shown) indicates that the evolved perturbations are acting to build the ridge immediately downstream of the land-falling storm and strengthen the PV gradient along the tropopause. This behavior is consistent with an enhancement of WCB outflow resulting in downstream ridge building as illustrated in Grams and Archambault (2016) in their study of extratropical transitions of TCs.

The forecast sensitivity to the initial state around the edges of the AR and to analyzed PV features seen in this case study are common to other cases examined for this period, and also consistent with previous results 
a) $24 \mathrm{~h} \mathrm{CTL} \mathrm{FCST} 850 \mathrm{WS}$

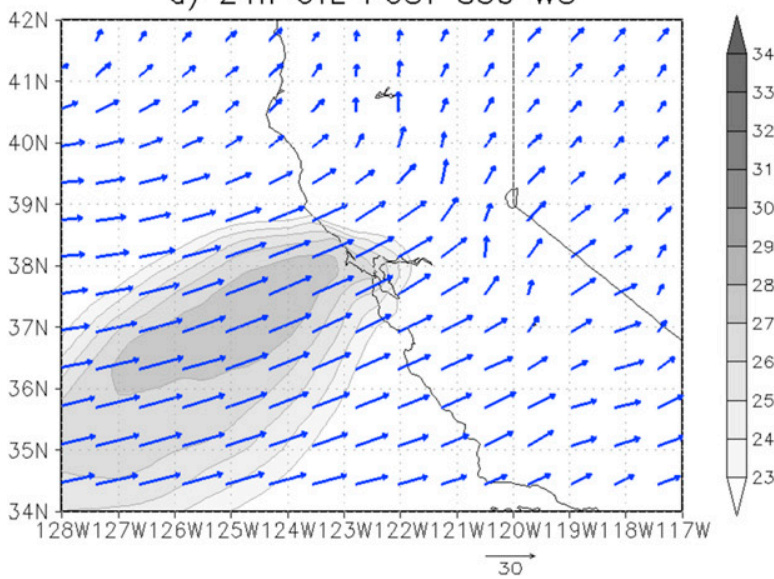

c) KE24 850 WS, WS'

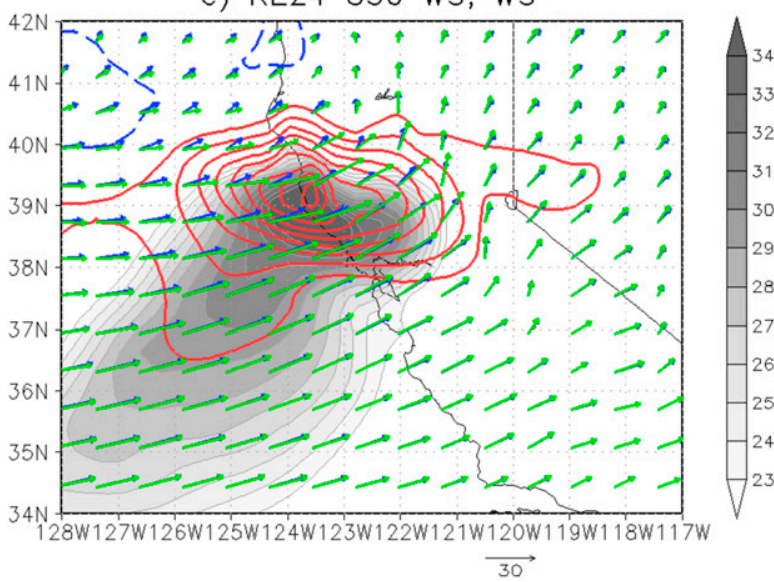

e) PR24 850 WS, WS'

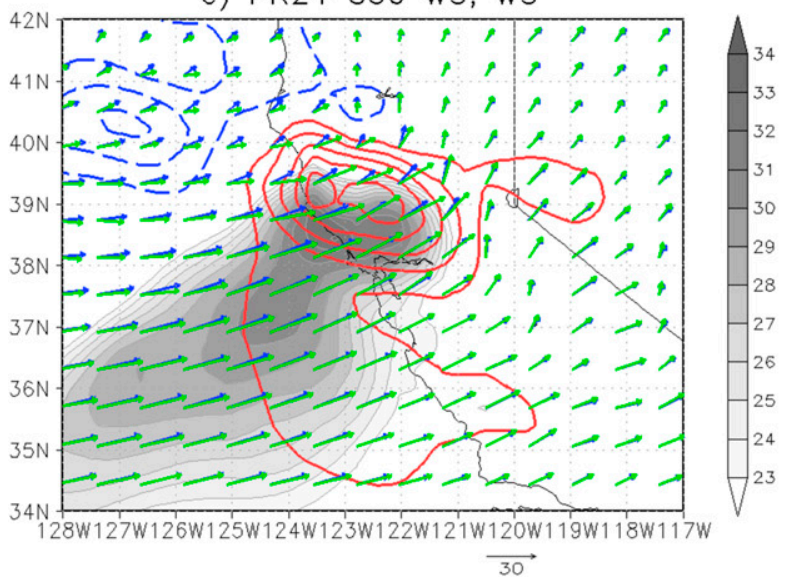

b) $24 \mathrm{~h}$ CTL FCST $21-24 \mathrm{~h}$ Precip

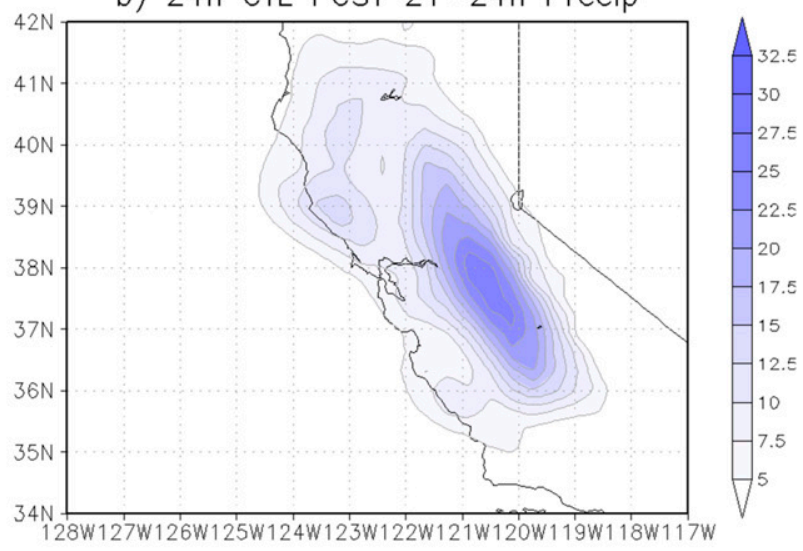

d) KE24 21-24h Precip, Precip'

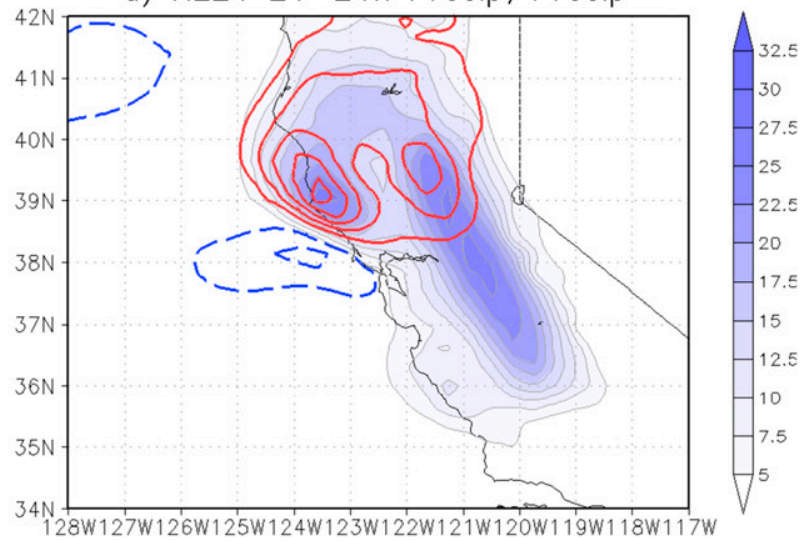

f) PR24 21-24h Precip, Precip'

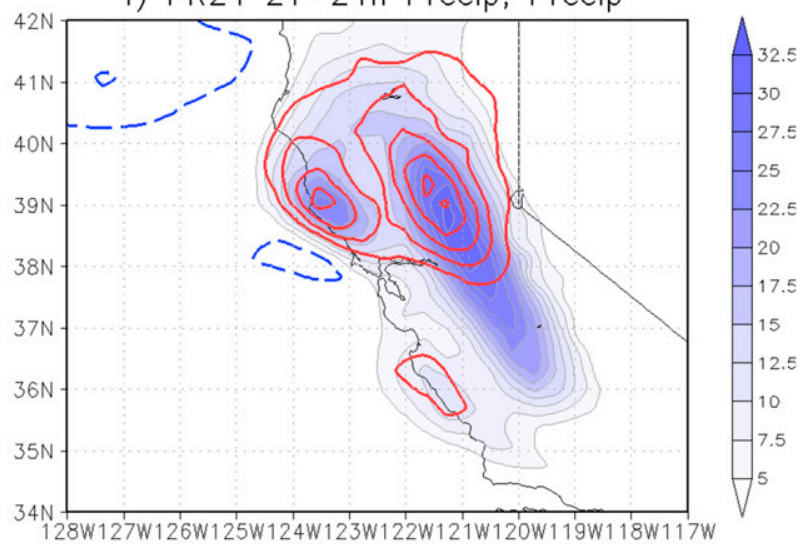

FIG. 6. 24-h forecast fields for the 1200 UTC 6 Feb 2017 case (valid at 1200 UTC 7 Feb 2017) for the (a),(b) control forecast, (c),(d) KE24 linear perturbed forecast, and (e),(f) PR24 linear perturbed forecast. (a),(c),(e) 850-hPa wind vectors (control winds in blue, perturbed winds in green), wind speed (gray shading, $\mathrm{m} \mathrm{s}^{-1}$ values given in color bar), and wind speed perturbations (control forecast wind speed - perturbed forecast wind speed, $\mathrm{ci}=2 \mathrm{~m} \mathrm{~s}^{-1}$, positive values red, negative values blue). (b),(d),(f) 21-24-h accumulated precipitation (blue shading, $\mathrm{mm}$ values given in color bar) and precipitation perturbation ( $\mathrm{ci}=2.5 \mathrm{~mm}$, positive values red, negative values blue). 
(e.g., Doyle et al. 2014; Reynolds et al. 2001). The implications for predictability and adaptive observing experiments are that it is important to minimize analysis errors in and around ARs at the top of the boundary layer and in the inflow and ascent regions of WCBs, and to account for this initial uncertainty in ensemble design for forecasts of both winds and precipitation. Analysis and forecast uncertainty near the top of the boundary layer is found to be primarily responsible for water vapor transport forecast uncertainty (Lavers et al. 2018), and significant uncertainty has been found in the inflow WCB region (Schäfler et al. 2011), which in turn has a substantial impact on WCB evolution (Schäfler and Harnisch 2015). While the general sensitivity characteristics at initial time are fairly similar, the resulting impacts are quite different. It is reassuring that the adjoint results display the expected sensitivity to RF, but this also suggests that applications such as adaptive observation guidance should be metric dependent. In section 4 we show that the general characteristics for the entire January and February 2017 period are consistent with the case-study results.

\section{General characteristics}

\section{a. Initial characteristics}

Inspection of the average sensitivity characteristics can provide guidance on where to focus adaptive observing capabilities. Figure 7 shows the vertically averaged absolute value of the moisture optimal perturbations (Figs. 7a,c,e) and wind optimal perturbations (Figs. 7b,d,f) for KE24 (Figs. 7a,b), PR24 (Figs. 7c,d), and KE36 (Figs. 7e,f), averaged for all cases. The choice of optimal perturbations rather than sensitivity here means that days with weaker or stronger sensitivity maxima contribute equally to the average. Plots constructed based on sensitivity rather than optimal perturbations (not shown) look similar. The fields have been normalized by the domain maximum value to facilitate comparison between panels. The average Eady growth rate, calculated following Hoskins and Valdes (1990) for the 300-1000-hPa layer, are shown over the moisture optimal perturbation plots (red contours in Figs. 7a,c,e). The average IVT is shown over the wind optimal perturbation plots (blue vectors in Figs. 7b,d,e). Also included are triangles and circles showing the location of the maximum sensitivity for each case (the circles indicate the 20 cases with the largest sensitivity). In an averaged sense the KE and PR RF patterns are very similar. The moisture optimal perturbation maxima are located along the longitude band where the Eady growth rate is a maximum, consistent with Buizza and Palmer (1995) and Reynolds et al. (2001). The wind optimal perturbation maxima are located slightly south of the moisture maxima, in the latitudinal band associated with high IVT. The wind sensitivity (as indicated by the optimal perturbations) extends over a broader region than the moisture sensitivity. The temperature results (not shown) are similar to the wind results. The large scatter in the black circles and triangles illustrates the large case-to-case variability in the location of the maximum, reflecting large variability in synoptic patterns. Aircraft stationed in Hawaii and the west coast of North America (as in the CalWater and AR Recon field projects) are wellpositioned to sample the most frequent sensitive regions, but there are cases that would be out of reach. There does not seem to be any preferred geographic location of the fastest growing cases (circles) as opposed to the rest of the cases (triangles). As expected, the KE36 pattern extends farther westward than the KE24 pattern (PR36 results, not shown, look very similar to the KE36 results). As detailed in section $4 \mathrm{~b}$, these average initial locations and subsequent eastward progressions with forecast time are consistent with lower-tropospheric advective speeds.

Figure 8 shows the corresponding vertical cross sections, averaged between $20^{\circ}$ and $50^{\circ} \mathrm{N}$. The KE24 (Figs. $8 \mathrm{a}, \mathrm{b}$ ) and PR24 (Figs. 8c,d) results are again very similar. While both wind and moisture have maxima between 600 and $800 \mathrm{hPa}$, the wind patterns (Figs. 8b,e) are more expansive in the vertical than the moisture patterns (Figs. 8a,c), which are mostly restricted to below $500 \mathrm{hPa}$. C130 aircraft deploying dropsondes from an altitude of $300 \mathrm{hPa}$, as in the AR Recon project (Ralph 2018) would sample the moisture-sensitive altitudes well, and would cover much, but not all, of the windsensitive altitudes. There is a distinct westward tilt with height in the average pattern, reflecting, in part, the fact that individual sensitivity structures tend to tilt westward with height, against the shear. The upshear tilt with height of rapidly growing perturbations has been found in several previous studies (e.g., Kleist and Morgan 2005; Reynolds et al. 2001; Badger and Hoskins 2001; Doyle et al. 2014), and has often been related to the unshielding of PV anomalies (Orr 1907; Farrell 1982). Comparing the 24-h optimization time (Figs. 8a,b) to the 36-h optimization time (Figs. 8e,f) for the KF RF, the westward extension is clear for both the moisture and wind fields. The maximum moves farther westward for the wind field (about $10^{\circ}$ longitude) than the moisture field (about $5^{\circ}$ longitude). Some of this offset may be due to the fact that the wind sensitivity may be more centered on the WCB inflow region, where the moisture sensitivity may be strongest in the WCB ascent region, as was seen in the case study (section 3 ).

To evaluate the relative magnitude of sensitivity to different variables, we show box-and-whisker plots (Fig. 9) 
a) KE24 Eady Growth Rate; Moist. Opt. Pert.
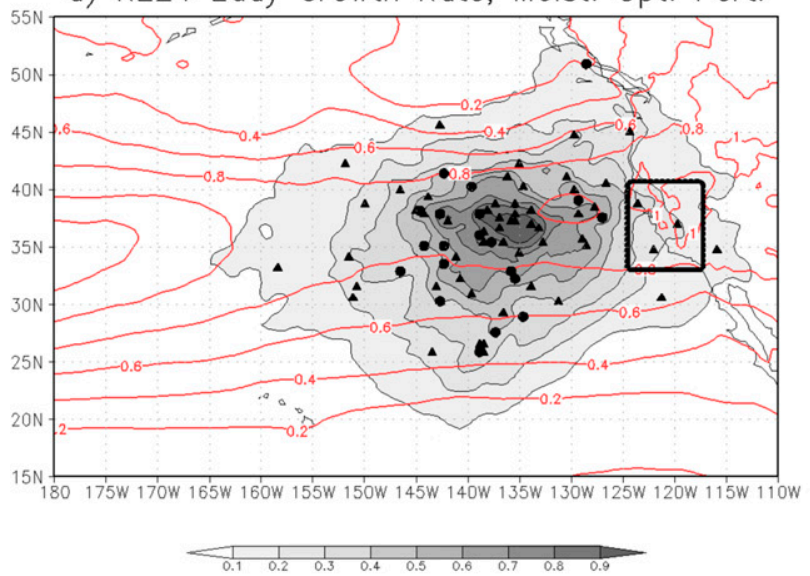

c) PR24 Eady Growth Rate; Moist. Opt. Pert.
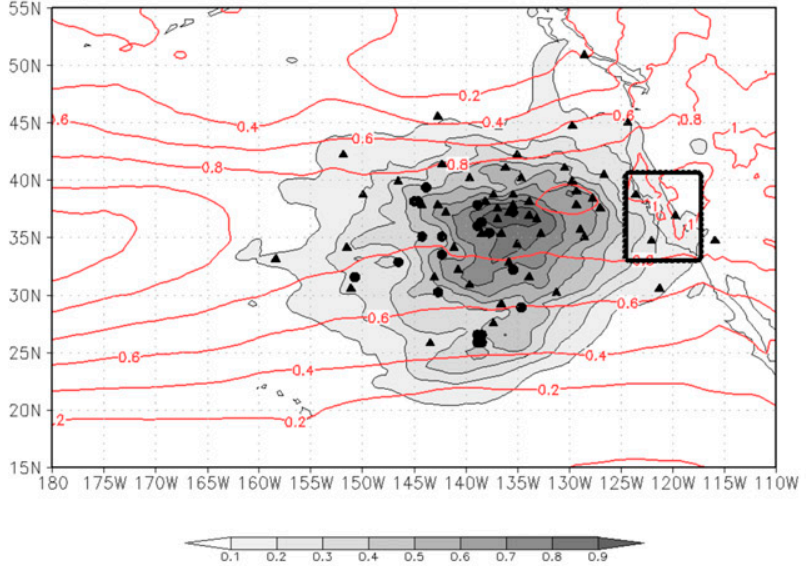

e) KE36 Eady Growth Rate; Moist. Opt. Pert.
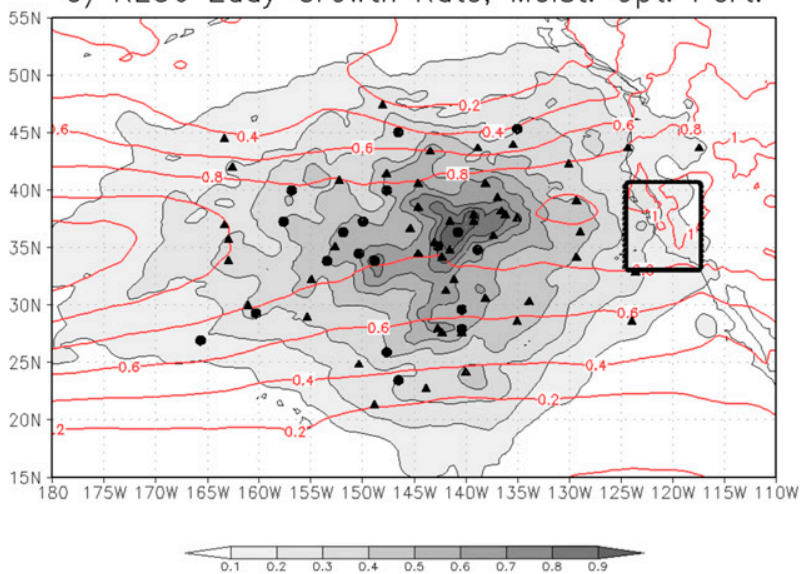

b) KE24 IVT; Wind Opt. Pert.
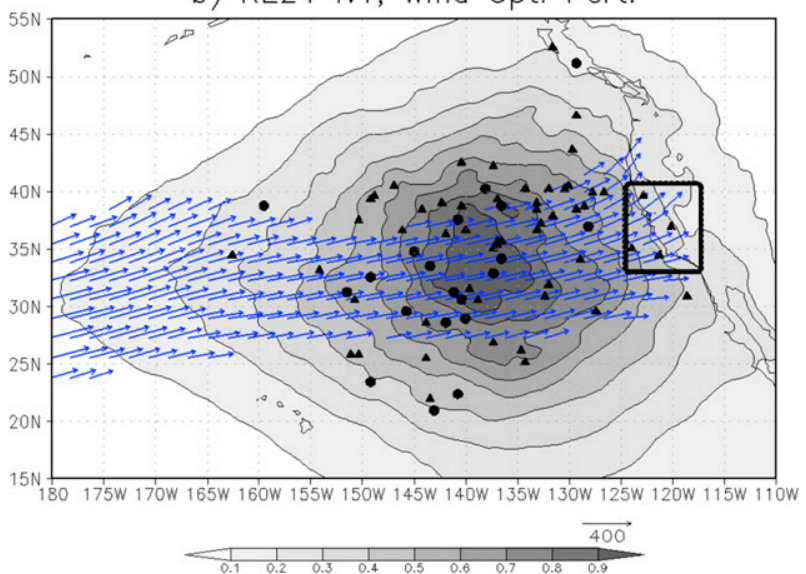

d) PR24 IVT; Wind Opt. Pert.

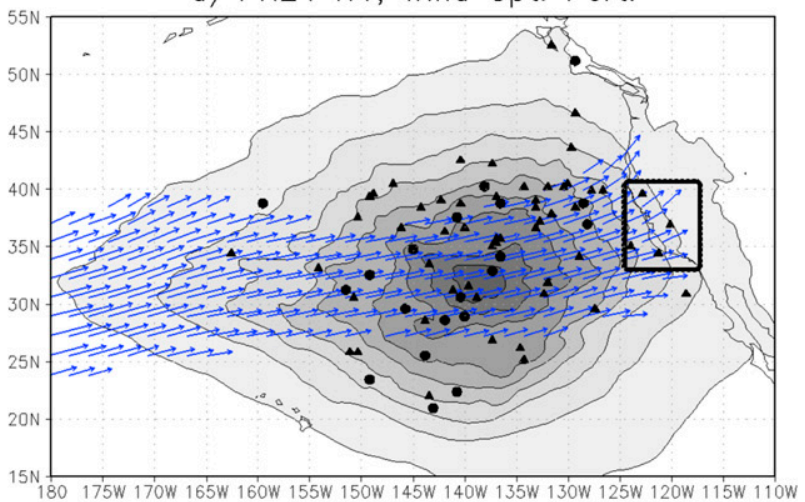

$\overrightarrow{400}$

f) KE36 IVT; Wind Opt. Pert.

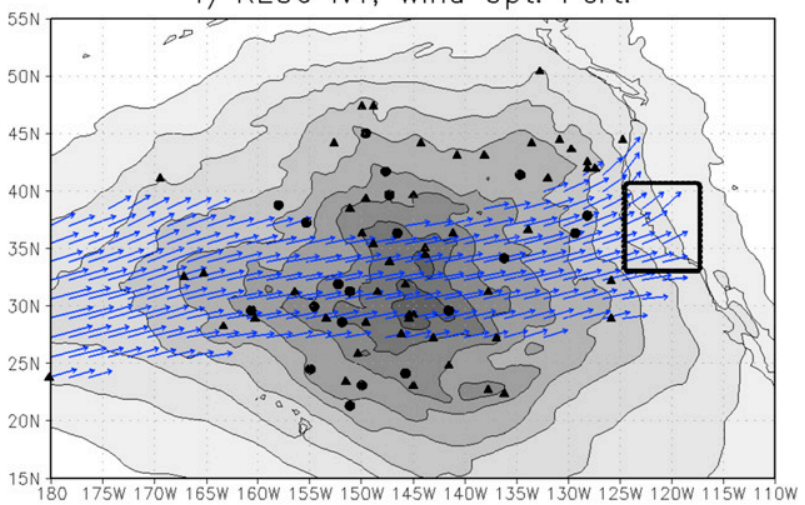

$\overrightarrow{400}$

FIG. 7. Vertically averaged optimal perturbations (gray shading, normalized by the domain maximum value) for (a),(c),(e) moisture and (b),(d),(f) wind for (a),(b) KE24, (c),(d) PR24, and (e),(f) KE36. Moisture panels in (a),(c),(e) also show Eady growth rate (red contours, day ${ }^{-1}$ ). The wind panels in (b),(d),(f) also show IVT (blue vectors, $\mathrm{kg} \mathrm{m} \mathrm{s}^{-1}$ ). The locations of individual maxima are indicated by triangles and circles (circles represent the 20 largest sensitivity cases). 
a) KE24 Moist. Opt. Pert.

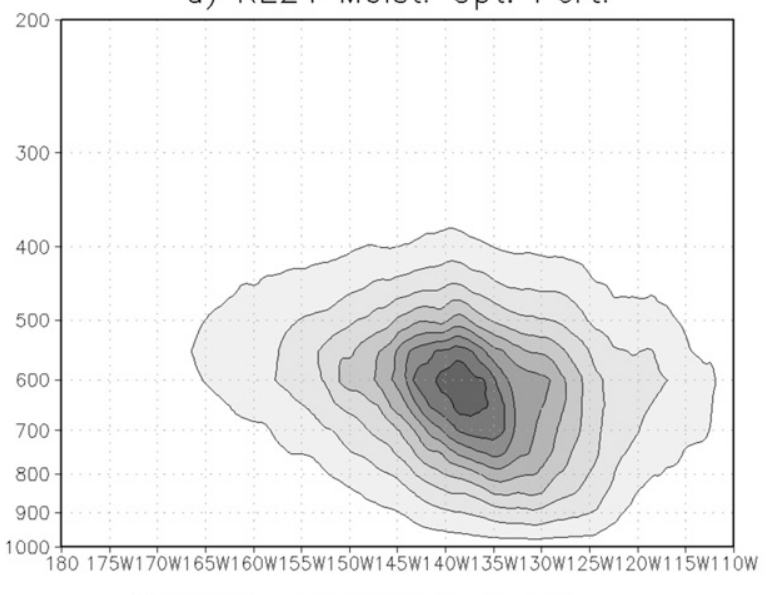

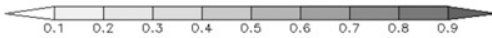

c) PR24 Moist. Opt. Pert.

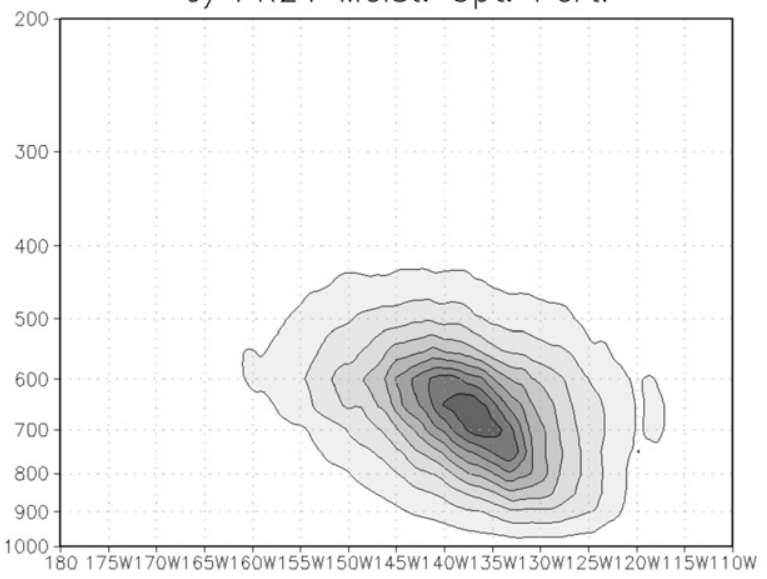

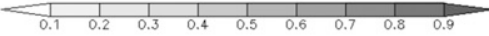

e) KE36 Moist. Opt. Pert.

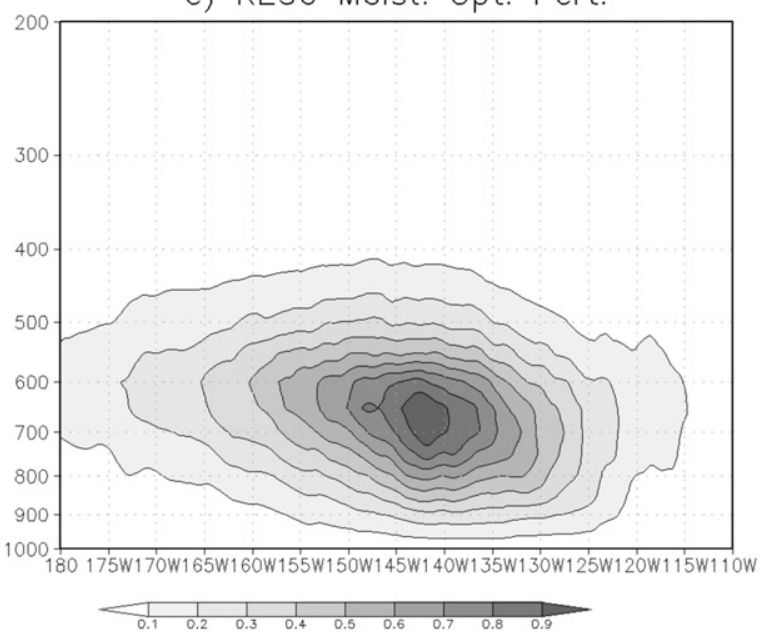

b) KE24 Wind Opt. Pert.

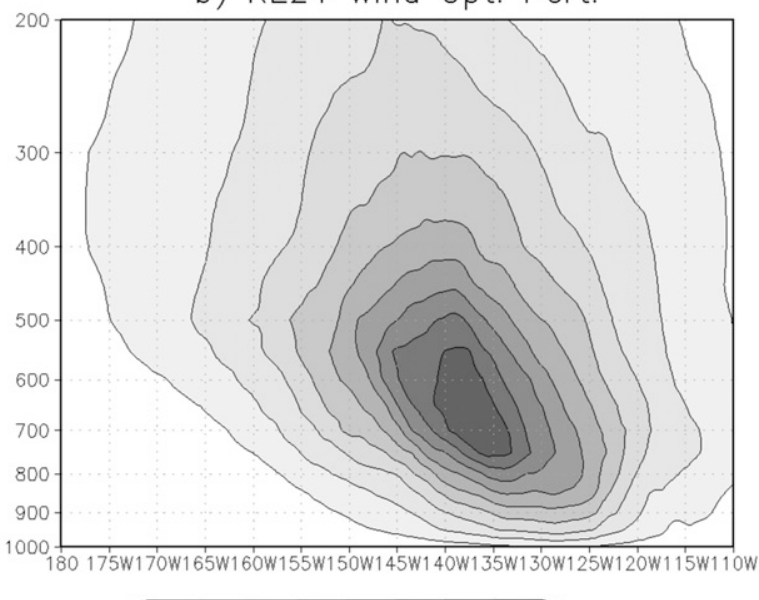

d) PR24 Wind Opt. Pert.

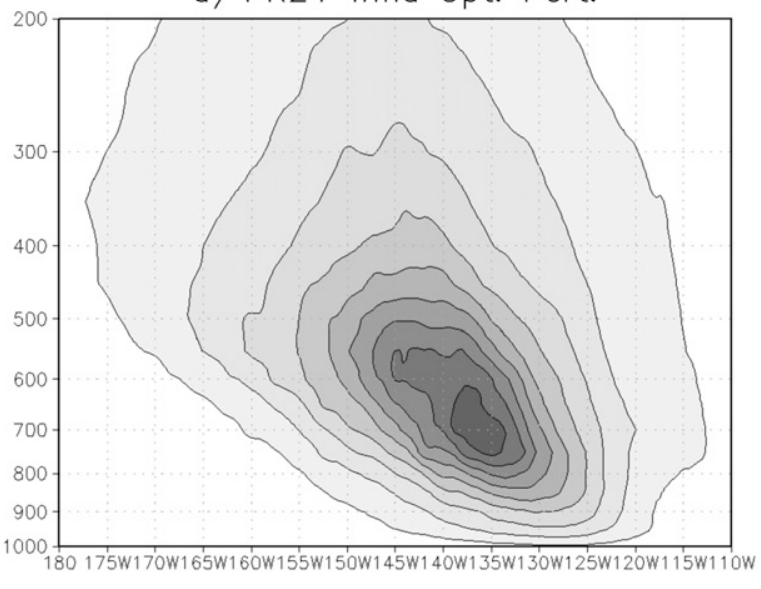

f) KE36 Wind Opt. Pert.

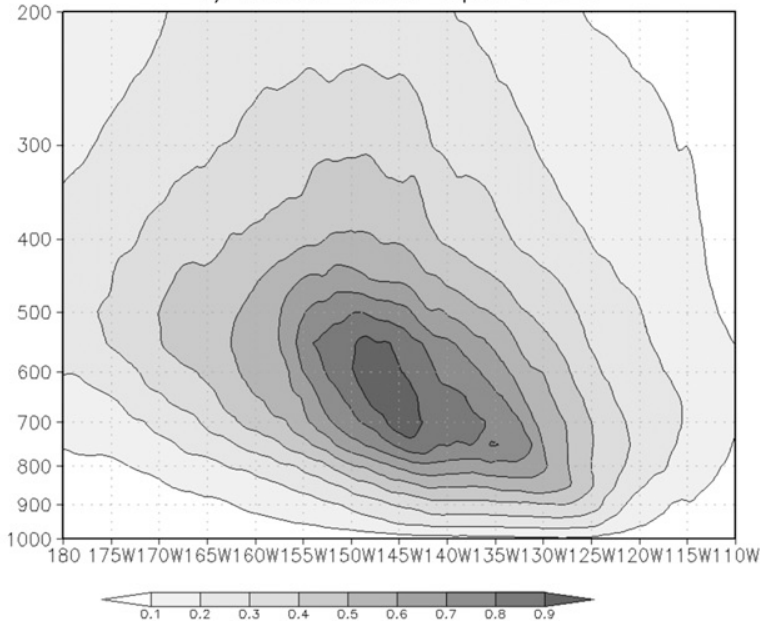

FIG. 8. Optimal perturbations (normalized by the domain maximum value) averaged between $20^{\circ}$ and $50^{\circ} \mathrm{N}$ for (a),(c),(e) moisture and (b),(d),(f) wind for (a),(b) KE24, (c),(d) PR24, and (e),(f) KE36. 
a) KE RF Sensitivity

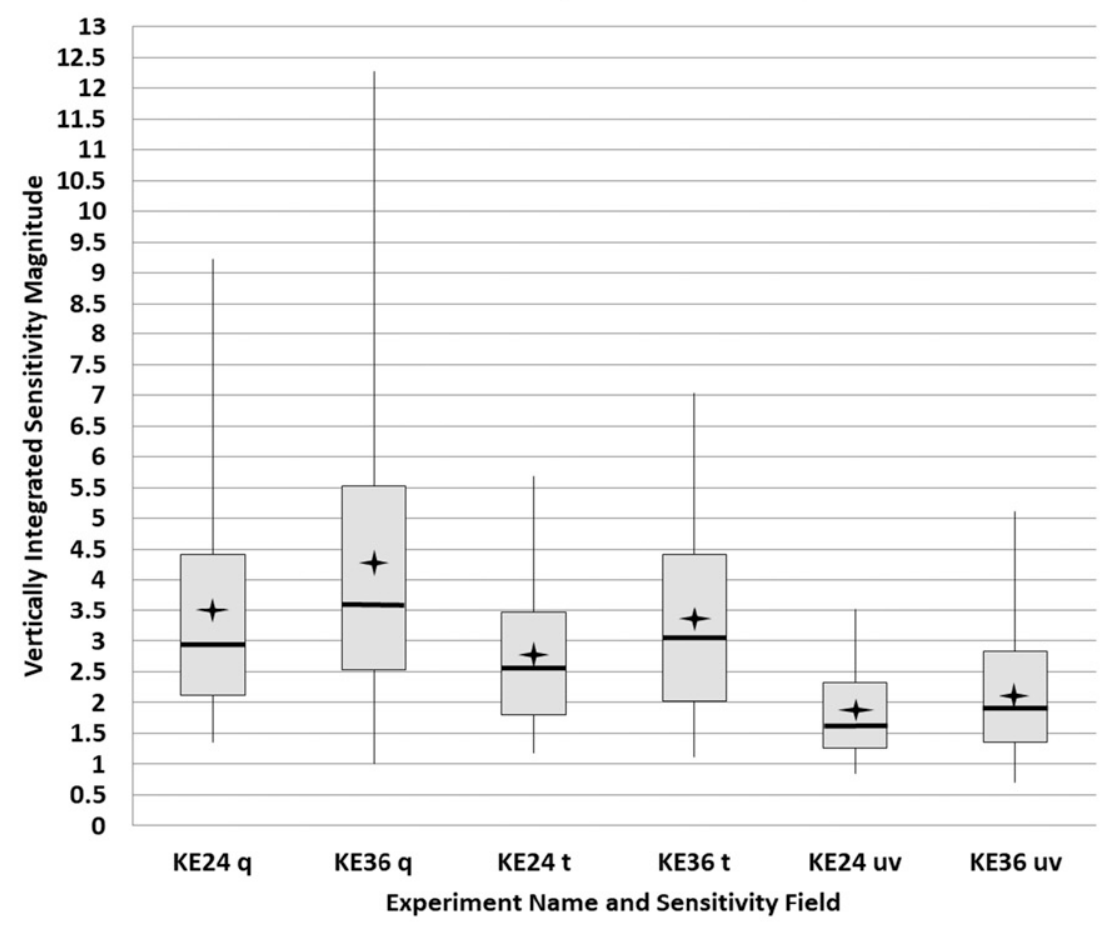

b) PR RF Sensitivity Magniutde

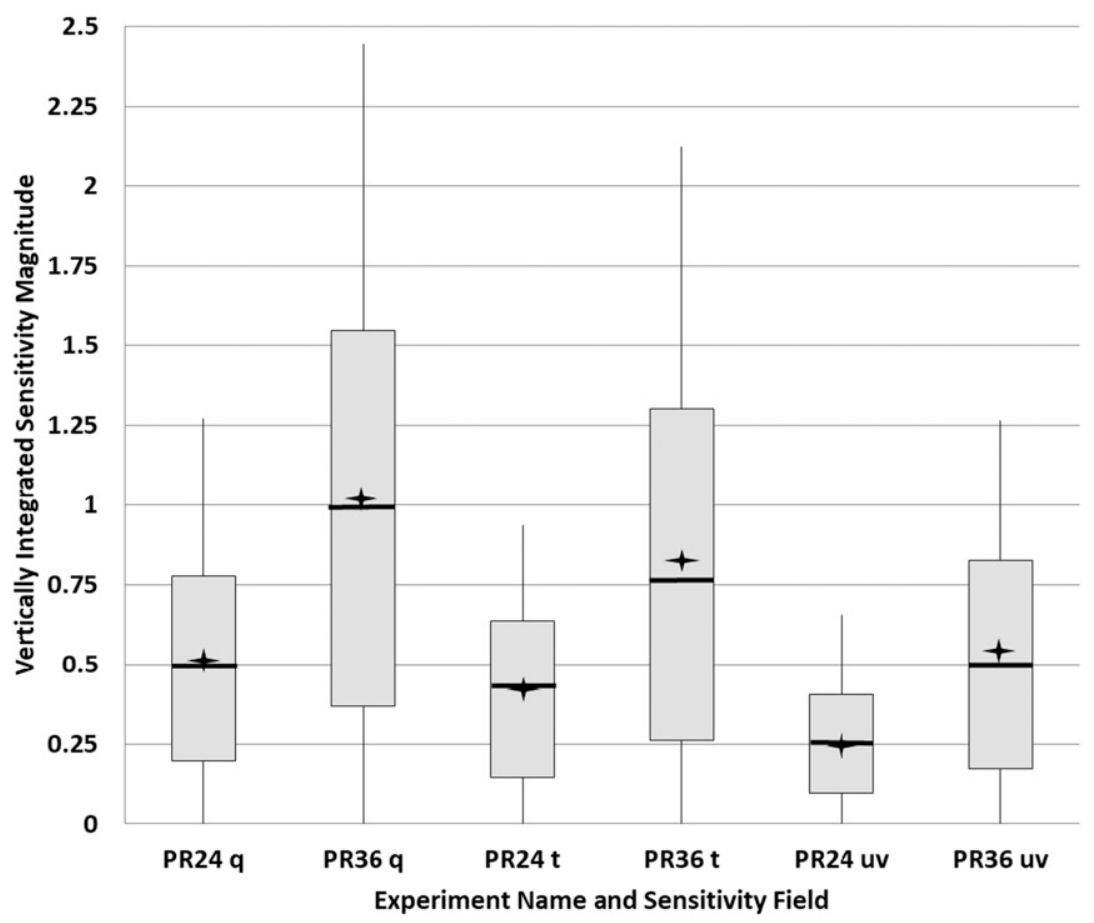

FIG. 9. Box-and-whisker plots for the area-averaged vertically integrated sensitivity for the (a) KE RF and (b) PR RF to changes in the initial moisture $q$, temperature $t$, and winds (sensitivity averaged for $u$ and $v$ ). The range of values is given by the vertical lines, the $25 \%$ and $75 \%$ values are given by the boxes, the median value is given by the thick horizontal line, and the average value is given by the cross. Units are $\mathrm{m}^{2} \mathrm{~s}^{-2}\left(\mathrm{~g} \mathrm{~kg}^{-1}\right)^{-1}$ for KE24 $q$ and KE36 $q, \mathrm{~m}^{2} \mathrm{~s}^{-2}\left(\mathrm{~m} \mathrm{~s}^{-1}\right)^{-1}$ for KE24 $u v$ and KE36 $u v$, and $\mathrm{m}^{2} \mathrm{~s}^{-2} \mathrm{~K}^{-1}$ for KE24 $t$ and KE36 $t$. Units are $\mathrm{mm}\left(\mathrm{g} \mathrm{kg}^{-1}\right)^{-1}$ for PR24 $q$ and PR36 $q, \mathrm{~mm}\left(\mathrm{~m} \mathrm{~s}^{-1}\right)^{-1}$ for PR24 $u v$ and PR36 $u v$, and $\mathrm{mm} \mathrm{K}^{-1}$ for PR24 $t$ and PR36 $t$. 
for the area-averaged vertically integrated sensitivity to moisture, temperature, and winds (average of the $u$ sensitivity and $v$ sensitivity) for KE24 and KE36 (Fig. 9a) and PR24 and PR36 (Fig. 9b). Note that the units for the different columns are different. The larger sensitivity for the 36-h optimization time as compared to the 24-h optimization time is consistent with potential perturbation growth increasing with forecast time. For the PR RF, this is also consistent with the fact that we are considering accumulated precipitation over a 6-h interval for PR36 and a 3-h interval for PR24. For both RFs and optimization times, the largest sensitivity is found for moisture, followed by temperature and then wind. This means that a $1 \mathrm{~g} \mathrm{~kg}^{-1}$ initial perturbation in moisture in a sensitive region can result in a larger change to forecasted winds or precipitation than a $1-\mathrm{K}$ initial perturbation in temperature, and about twice the change as a $1 \mathrm{~m} \mathrm{~s}^{-1}$ initial perturbation in either the zonal or meridional wind. This supports the importance of accurate moisture analyses and appropriate accounting for moisture uncertainty in ensemble design.

From both a general predictability standpoint, and from an adaptive observation standpoint, it is of interest to know if case-to-case variability in the magnitude of sensitivity is similar for the KE and PR RFs. Figure 10 shows scatterplots of the domain-averaged vertically integrated absolute values of the KE RF sensitivity versus the PR RF sensitivity for moisture (Fig. 10a) and winds (Fig. 10b).Temperature results not shown, are similar. Despite the positive correlations (from 0.62 to $0.75)$, there are cases when the wind forecast is quite sensitive but the precipitation forecast is not, and vice versa. These results, taken together with the case study, suggest that, if deploying adaptive observations to improve short-term forecasts, the choice of both when and where to deploy will be metric dependent. It may therefore be advantageous to tailor adaptive observing guidance to the type of hazard that is anticipated.

\section{b. Evolution of optimal perturbations}

We can use the sensitivity-derived optimal perturbations to examine how the characteristics of these perturbations change as they evolve, both in a linear and nonlinear sense. To examine the perturbation relative growth and propagation eastward, Fig. 11 shows the vertically integrated magnitude of the case-averaged linear optimal perturbations, averaged from $20^{\circ}$ to $50^{\circ} \mathrm{N}$, as a function of longitude for KE RFs (Figs. 11a,b ) and PR RFs (Figs. 11c,d). Water vapor perturbations are shown in a and $c$, and wind speed perturbations are shown in $b$ and d. Different colors correspond to different forecast lead times, with the solid curves corresponding to the $36-\mathrm{h}$ optimization time cases and the dashed curves corresponding to the 24-h optimization time cases. The maxima for all sets of curves increases with time and moves eastward at approximately between $13^{\circ}$ and $16^{\circ}$ of longitude per day, which at $35^{\circ} \mathrm{N}$ is approximately $13-17 \mathrm{~m} \mathrm{~s}^{-1}$. This is consistent with the average zonal wind speed at $750 \mathrm{hPa}$ at $35^{\circ} \mathrm{N}$ between $150^{\circ} \mathrm{W}$ and the North American coast. The final-time curves are a maximum within the longitudinal range $\left(125^{\circ}-117.5^{\circ} \mathrm{W}\right)$ of the RF box, as expected. While the maximum values for the vertically integrated moisture and wind perturbations are reached at $24 \mathrm{~h}$ for KE24 (dashed red curve in Figs. 11a,b) and 36h for KE36 (solid purple curve in Figs. 11a,b), they are reached at $18 \mathrm{~h}$ for PR24 (green dashed curve) and $30 \mathrm{~h}$ for PR36 (solid yellow curve) for water vapor (Fig. 11c). ${ }^{5}$ This is consistent with the fact that accumulated precipitation over the last 3-6h of the forecast would be maximized through large fluxes into the RF region during that period. The regular growth and monotonic progression eastward show that the final-time perturbations are not occurring through remote excitation of an instability in the RF box, as can happen in NWP perturbation experiments (Ancell et al. 2018).

To illustrate how the optimal perturbations evolve in the vertical, Fig. 12 shows the profiles of the linearly evolving absolute value of the optimal perturbations (averaged between $20^{\circ}-50^{\circ} \mathrm{N}$ and $170^{\circ}-125^{\circ} \mathrm{W}$ ) as a function of pressure for the 36-h optimization cases for water vapor (Fig. 12a), wind speed (Fig. 12b), and temperature (Fig. 12c). We normalize by the domainaveraged values at initial time such that $x$-axis values may be related to perturbation growth. In contrast to Fig. 11, here the solid curves correspond to KE36 and the dashed curves correspond to PR36. The 24-h optimization time cases (not shown) are very similar to the 0-24-h curves for the 36-h optimization time cases. Figure 12d shows RF box-averaged profiles for the wind speed, water vapor, and horizontal vapor transport. Both the initial and evolved profiles vary considerably by field. Consistent with the height-longitude profiles shown in Fig. 8 and the case study in section 3, the initial moisture optimal perturbation profiles peak between 600 and $700 \mathrm{hPa}$, just above the maximum in horizontal vapor transport between 750 and $900 \mathrm{hPa}$, and taper off sharply above $500 \mathrm{hPa}$. The initial wind and temperature profiles peak at similar pressure levels, but taper off much more gradually with height. As the moisture perturbations evolve, the altitude of the maximum perturbation descends to approximately $850 \mathrm{hPa}$, consistent

\footnotetext{
${ }^{5}$ Values for water vapor for PR24 at $21 \mathrm{~h}$ (not shown) are comparable to those at $18 \mathrm{~h}$.
} 

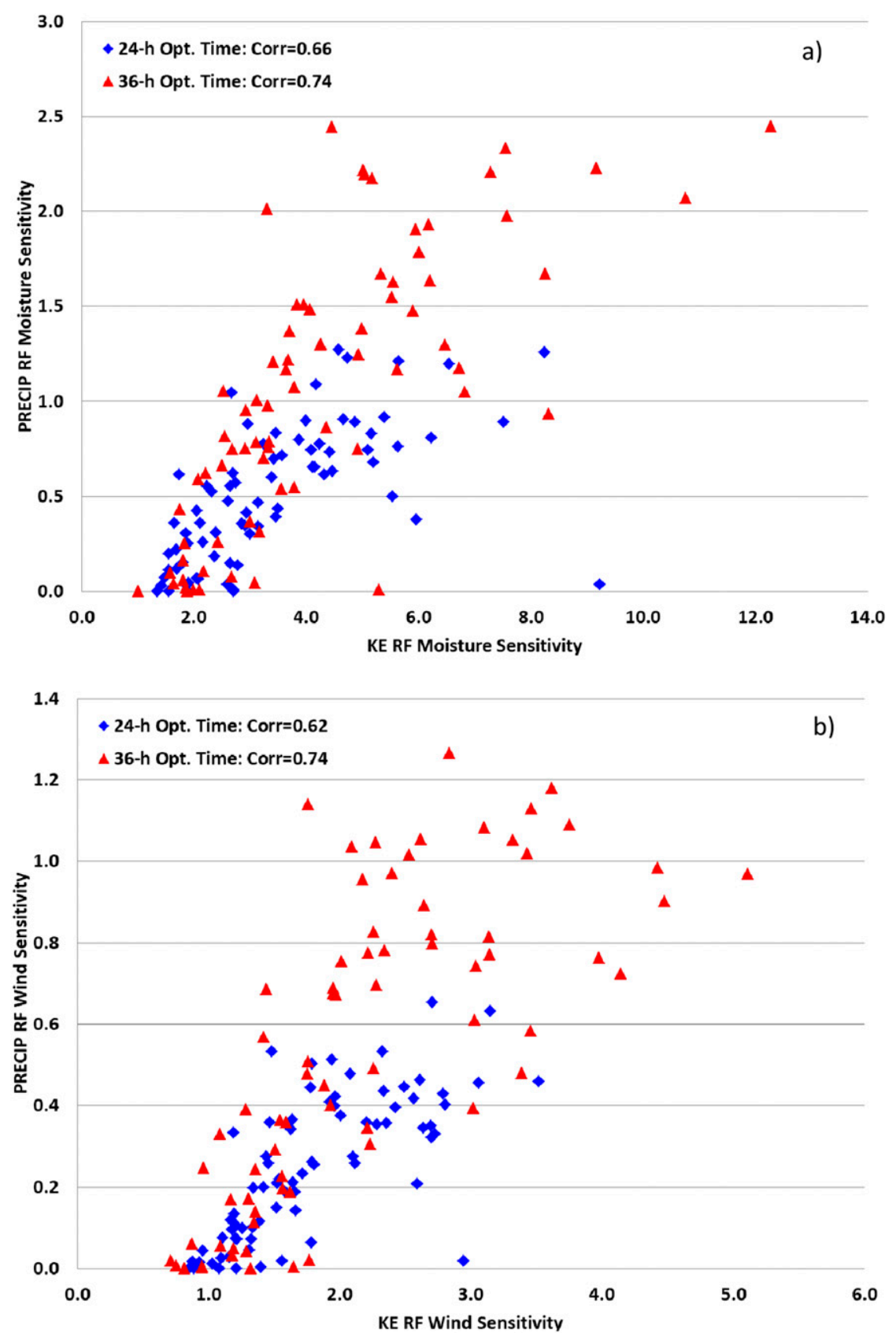

FIG. 10. Scatterplot for the domain-averaged vertically integrated absolute value of KE RF sensitivity ( $x$ axis) vs the PR RF sensitivity ( $y$ axis), for the 24-h optimization time (blue diamonds) and 36-h optimization time (red squares) to (a) moisture and (b) winds. Correlation values are provided in key. Results for temperature (not shown) are similar. Units are $\mathrm{m}^{2} \mathrm{~s}^{-2}\left(\mathrm{~g} \mathrm{~kg}^{-1}\right)^{-1}$ for KE RF moisture sensitivity, $\mathrm{m}^{2} \mathrm{~s}^{-2}\left(\mathrm{~m} \mathrm{~s}^{-1}\right)^{-1}$ for KE RF wind sensitivity, $\mathrm{mm}\left(\mathrm{g} \mathrm{kg}^{-1}\right)^{-1}$ for PR moisture sensitivity, and $\mathrm{mm}\left(\mathrm{m} \mathrm{s}^{-1}\right)^{-1}$ for PR wind sensitivity.

with the level of maximum horizontal vapor transport. The temperature perturbations evolve to have two maxima, in the mid- to lower troposphere and the tropopause level, probably reflecting changes in the tropopause height. The wind perturbations evolve to have a fairly broad peak at approximately $350 \mathrm{hPa}$, below jet level, similar to previous findings (e.g., Buizza and Palmer 1995; Doyle et al. 2014). In an average sense, the profiles of the optimal perturbations for KE36 (solid curves) and PR36 (dashed curves) are very similar, although the PR36 perturbation growth is for the most part slightly faster. We have also included the domain averages of 
a) KE RF Water Vapor

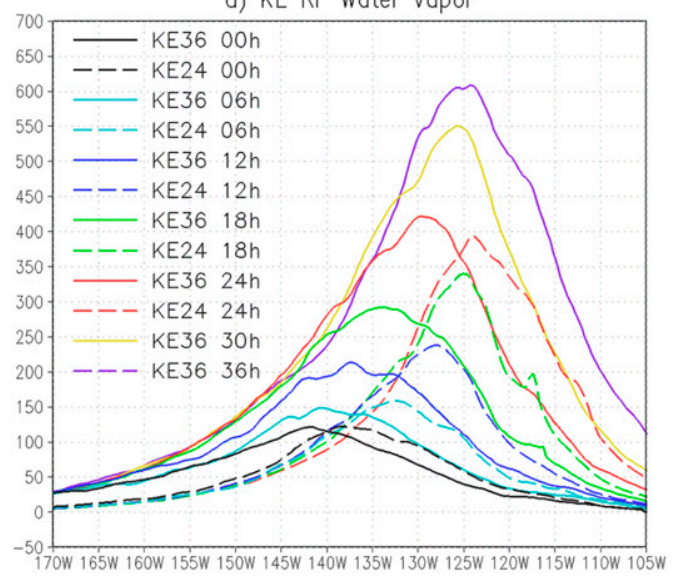

c) PR RF Water Vapor

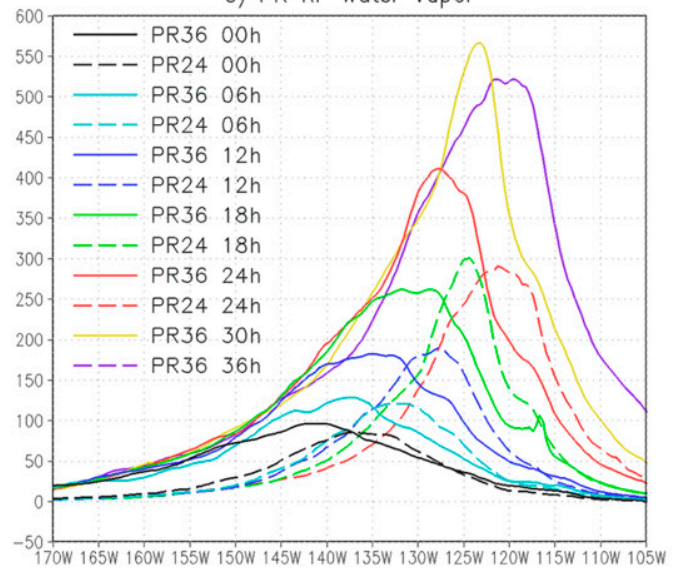

b) KE RF Wind Speed

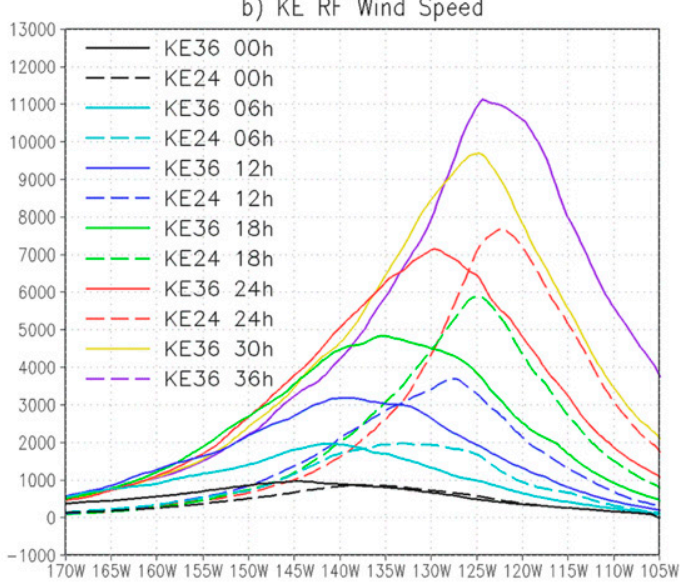

d) PR RF Wind Speed

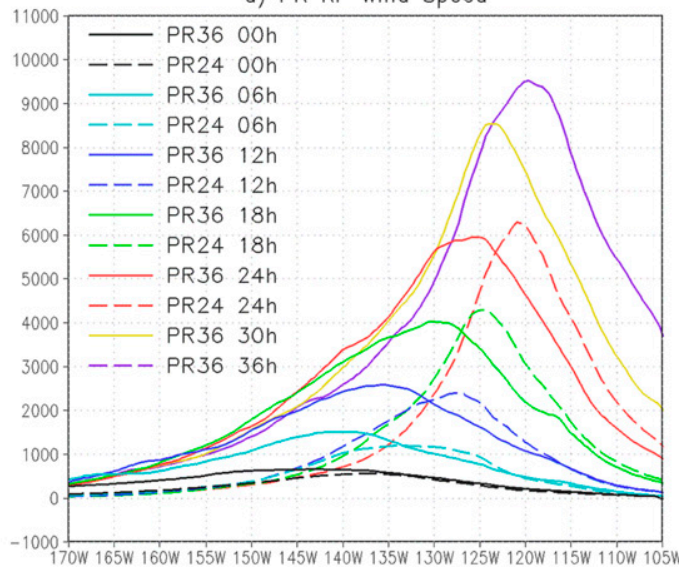

FIG. 11. The vertically integrated magnitude of the case-averaged optimal perturbations, averaged from $20^{\circ}$ to $50^{\circ} \mathrm{N}$, for (a),(c) moisture $\left(\mathrm{g} \mathrm{kg}^{-1}\right)$ and (b), (d) winds $\left(\mathrm{m} \mathrm{s}^{-1}\right.$ ) for the (a),(b) KE RF and (c),(d) PR RF. Different forecast times are indicated by the different color curves as given in key. The solid curves correspond to the 36-h cases and the dashed curves correspond to the $24-\mathrm{h}$ cases. The 0 -h wind curves are multiplied by a factor of 10 . The response function box lies between $125^{\circ}$ and $117.5^{\circ} \mathrm{W}$.

the optimal perturbations at initial time (gray curves). The fact that the gray curves are very close to zero relative to the black curves indicates the positive and negative lobes of the initial sensitivity largely cancel each other out when a domainwide average is taken. This along with the rapid growth rate is evidence that the perturbation evolution is produced through dynamic and thermodynamic processes, not simple advection.

The initial wind profiles in Figs. 11 and 12 are multiplied by a factor of 10 because the magnitude of the wind perturbations at tau 0 are very small compared to the magnitude of the wind perturbations at later forecast times. This early rapid growth in the wind field is illustrated in Table 2, which shows the average growth rates for different time intervals for the moisture, temperature, and wind components of the linearly evolved optimal perturbations. From 0 to $6 \mathrm{~h}$, the moisture component of the optimal perturbation has a relatively small growth rate (less than $1.0 \mathrm{day}^{-1}$ ), while the temperature component growth rate is between 3.6 and $4.2 \mathrm{day}^{-1}$, and the wind component growth rate (averaged for the zonal and meridional components) is very rapid (around 12 day $^{-1}$ ). This is indicative of a rapid initial adjustment in which the moisture perturbation elicits a strong response in winds and temperature, and is consistent with the case study shown in section 3. The growth rates become similar for the 6-24-h forecast interval (1.15-1.34 day ${ }^{-1}$ for moisture, 1.33$1.56 \mathrm{day}^{-1}$ for temperature, and $1.45-1.73 \mathrm{day}^{-1}$ for winds). Growth rates for all fields diminish during the 24-36-h interval, and range from 0.71 to $0.84 \mathrm{day}^{-1}$ for all fields. These growth-rate characteristics are similar to those found for a TC-Kelvin wave case considered in Reynolds et al. (2016). 
a) Water Vapor Pert.

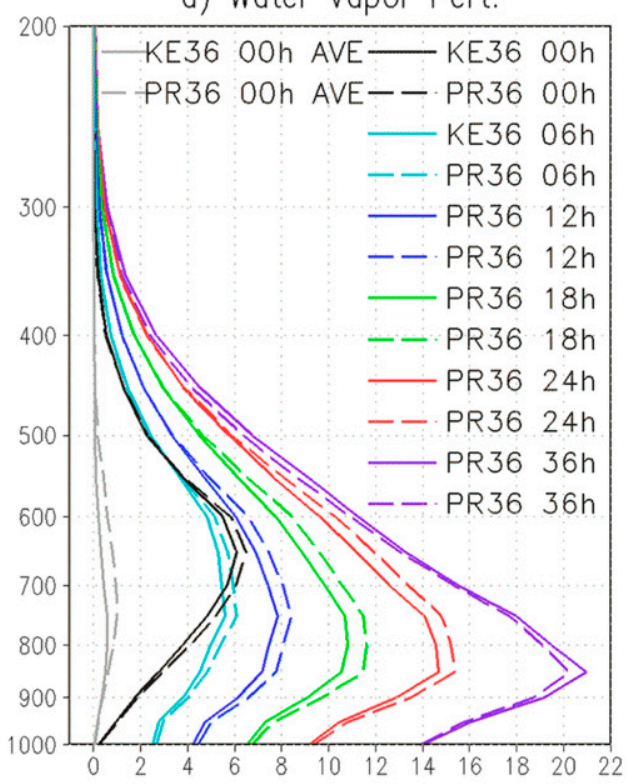

c) Temperature Pert.

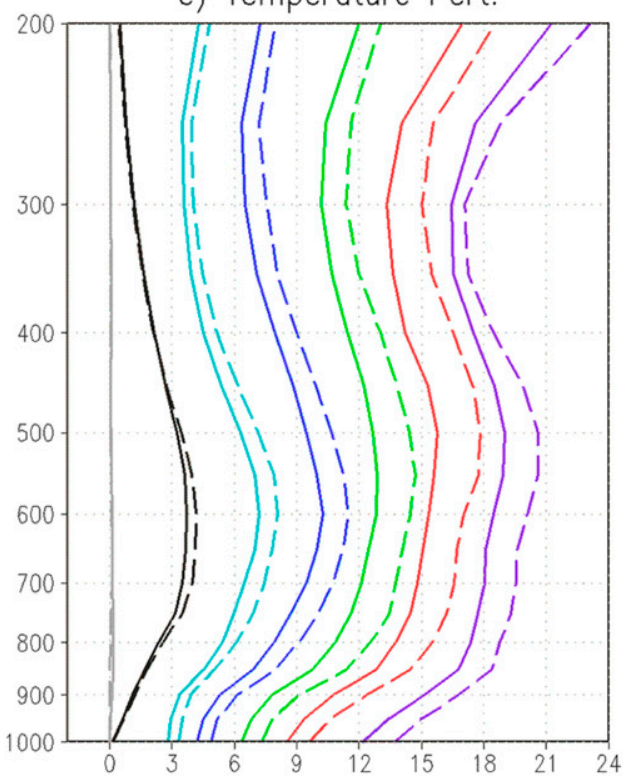

b) Wind Speed Pert.

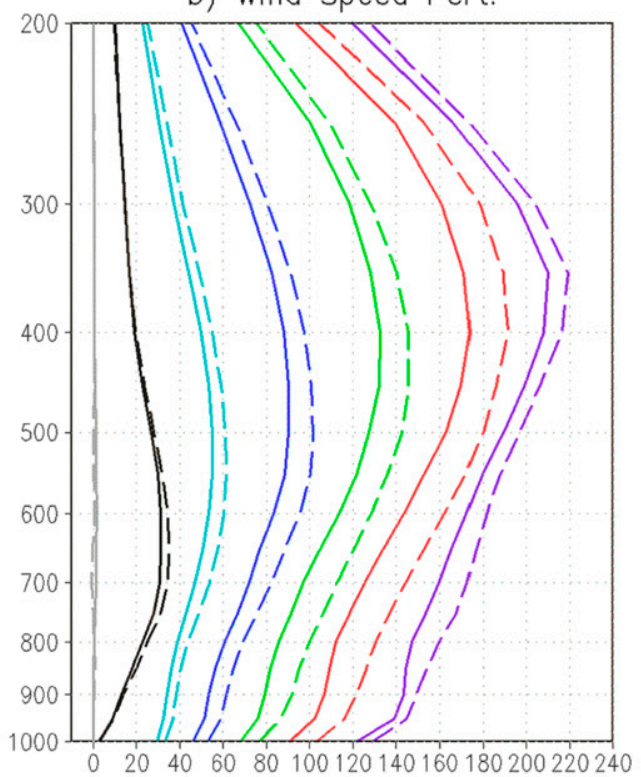

d) Vapor Transport, Water Vapor, Wind Speed

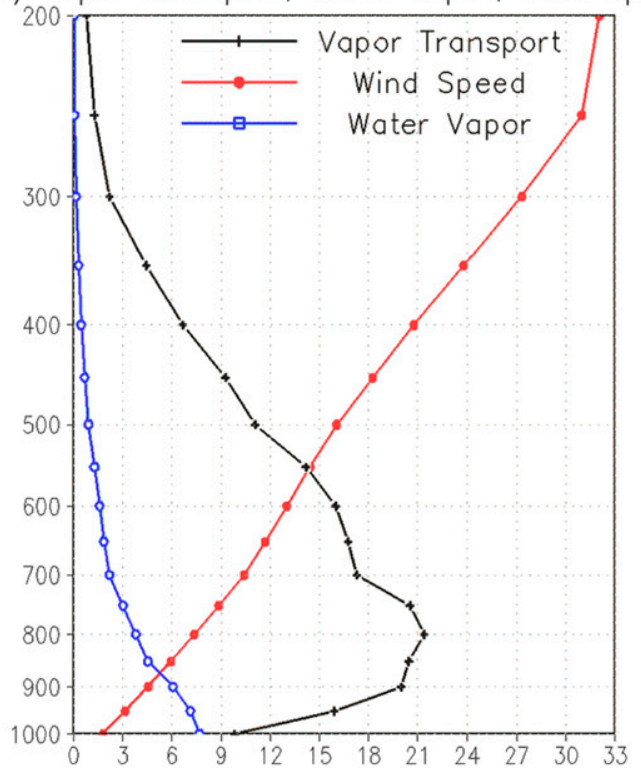

FIG. 12. Vertical profiles of area-averaged absolute value of the optimal perturbations (normalized by the domain average value at initial time) for the 36-h optimization cases for (a) moisture, (b) winds, and (c) temperature. Solid curves are for the KE RF and dashed curves are for the PR RF. Different forecast times in (a)-(c) are indicated by the different color curves as given in the key in (a). The gray curves represent the 0 -h area-averaged optimal perturbations. The 0 - $\mathrm{h}$ wind curves are multiplied by a factor of 10 . The lower right panel shows the average profiles of wind speed $\left(\mathrm{m} \mathrm{s}^{-1}\right.$, red), water vapor $\left(\mathrm{g} \mathrm{kg}^{-1}\right.$, blue), and vapor transport $\left(\mathrm{m} \mathrm{g} \mathrm{s}^{-1} \mathrm{~kg}^{-1}\right.$ black).

While we have thus far focused on the linear evolution of the perturbations, we also need to assess how these perturbations, optimized under the tangent linear constraint, evolve in the full nonlinear model. Figure 13 shows the vertical profiles of the final-time absolute value of the optimal water vapor (Fig. 13a), temperature
(Fig. 13b), zonal wind (Fig. 13c), and meridional wind (Fig. 13d) perturbations averaged over the RF box for KE36 (black) and PR36 (red), for the linear-evolved (solid) and nonlinear-evolved (dashed) perturbations. Comparison of the solid (linear) and dashed (nonlinear) curves indicates that the nonlinear moisture 
TABLE 2. Average growth rates $\left(\mathrm{day}^{-1}\right)$ of the optimal perturbations for different forecast time intervals.

\begin{tabular}{lcrrrr}
\hline \hline \multirow{4}{*}{ Moisture } & $\begin{array}{c}\text { Time } \\
\text { intervals (h) }\end{array}$ & KE24 & KE36 & PR24 & PR36 \\
& $0-6$ & 0.65 & 0.65 & 0.87 & 0.62 \\
& $6-24$ & 1.15 & 1.32 & 1.11 & 1.34 \\
Temperature & $0-24$ & 1.03 & 1.16 & 1.05 & 1.16 \\
& $24-36$ & & 0.79 & & 0.71 \\
& $0-6$ & 4.21 & 3.59 & 3.69 & 3.93 \\
Winds & $6-24$ & 1.34 & 1.45 & 1.56 & 1.46 \\
& $0-24$ & 2.05 & 1.98 & 2.1 & 2.08 \\
& $24-36$ & & 0.83 & & 0.84 \\
& $0-6$ & 12.44 & 11.97 & 11.94 & 12.27 \\
& $6-24$ & 1.46 & 1.60 & 1.73 & 1.62 \\
& $0-24$ & 4.21 & 4.19 & 4.28 & 4.28 \\
& $24-36$ & & 0.78 & & 0.78 \\
\hline
\end{tabular}

perturbations are about $20 \%-25 \%$ smaller than the linear moisture perturbations. For winds, the nonlinear perturbations differ from the linear perturbations by less than $10 \%$ (the nonlinear perturbations tend to be larger than the linear perturbations in the upper troposphere, and smaller in the lower troposphere). For temperature, the nonlinear perturbations are larger than the linear perturbations by about $10 \%-$ $20 \%$ in the lower troposphere and by as much as $30 \%$ in the upper troposphere. For KE24 and PR24 (not shown) the match between nonlinear and linear results is closer. An exact match between linear and nonlinear perturbations is not expected given that the forecast evolves nonlinearly and we have chosen a dynamic period with very moist flow. However, these diagnostics confirm that these optimal perturbations derived from the adjoint are very effective at producing rapid perturbation growth in the nonlinear forecast system.

Also included in Fig. 13 are the vertical profiles of the final-time linear perturbations averaged over the RF box (indicated by the dotted curves). In contrast to the initial time results shown in Fig. 12, the RF box-averaged values at final time are a significant fraction of the average magnitude of the perturbations. The evolved optimal perturbations enhance moisture in the lower troposphere, especially for PR36. Both KE and PR RFs show increased temperature through much of the troposphere, but there is a more-pronounced warming in the midtroposphere and a more-pronounced cooling in the upper troposphere for the PR RFs than for the KE RFs. This is consistent with more midlevel latent heating due to condensation in the PR cases. The enhanced westerlies in the lower troposphere for the KE RFs are consistent with an enhancement of the low-level wind speed, given the prevailing westerly winds. The increased low- and midlevel moisture and increased southerlies and westerlies are consistent with orographically induced precipitation enhancement over much of California.

Table 3 shows the nonlinear and linear low-level wind speed and accumulated precipitation forecast perturbations over the RF box averaged for all cases. Despite the similarities in the average location of the KE and PR RF initial optimal perturbations shown in Figs. 7 and 8, the resulting changes to precipitation and wind forecasts are substantially different. The KE RF optimal initial perturbations are about twice as effective at producing wind forecast changes as the PR RFs. The PR RF initial optimal perturbations are in turn almost twice as effective at producing precipitation forecast changes as the KE RFs. Table 3 also allows for a comparison of nonlinear and linear perturbation growth. Nonlinear average values for the wind field perturbations are between $78 \%$ and $86 \%$ as large as the linear values. For precipitation, the nonlinear values are $79 \%$ and $70 \%$ of the linear values for KE24 and KE36, and 103\% and 94\% for PR24 and PR36. Correlations between the magnitudes of the nonlinear and linear perturbations over all the individual cases are $85 \%-87 \%$ at $24 \mathrm{~h}$ and $81 \%-82 \%$ at $36 \mathrm{~h}$ for the wind fields. The correlations for precipitation are comparably high at $24 \mathrm{~h}(84 \%-87 \%)$, but drop off to $68 \%-74 \%$ for $36 \mathrm{~h}$. The drop-off in the correlation with optimization time is expected, as the linear approximation becomes less appropriate in general as optimization time is increased. These results indicate that despite the tangent-linear assumption, these optimal perturbations are very effective at producing fast growing perturbations between two nonlinear forecasts as well as capturing case-to-case variability in perturbation growth.

\section{c. Relationship to forecast error and forecast uncertainty}

The utility of using adjoint-based tools for applications such as predictability studies and adaptive observations is premised upon the concept that, on average, forecasts that are very sensitive to initial condition perturbations would tend to have larger forecast errors. Figure 14a shows the mean absolute wind speed errors in the RF region at final time ( 24 or $36 \mathrm{~h}$ ) in the control COAMPS forecast as verified by the GFS analysis compared with the domain-averaged absolute value of the initial-time wind sensitivity. The correlations are 0.64 for KE24 and 0.67 for KE36. Similar results (not shown) are found for the temperature and moisture sensitivities. A perfect correlation between sensitivity and forecast error is not expected. Forecast error may also be caused by nonlinear growth of initial errors, model error, and the potential presence of initially large but slow-growing errors. In addition, the projection of the initial error 

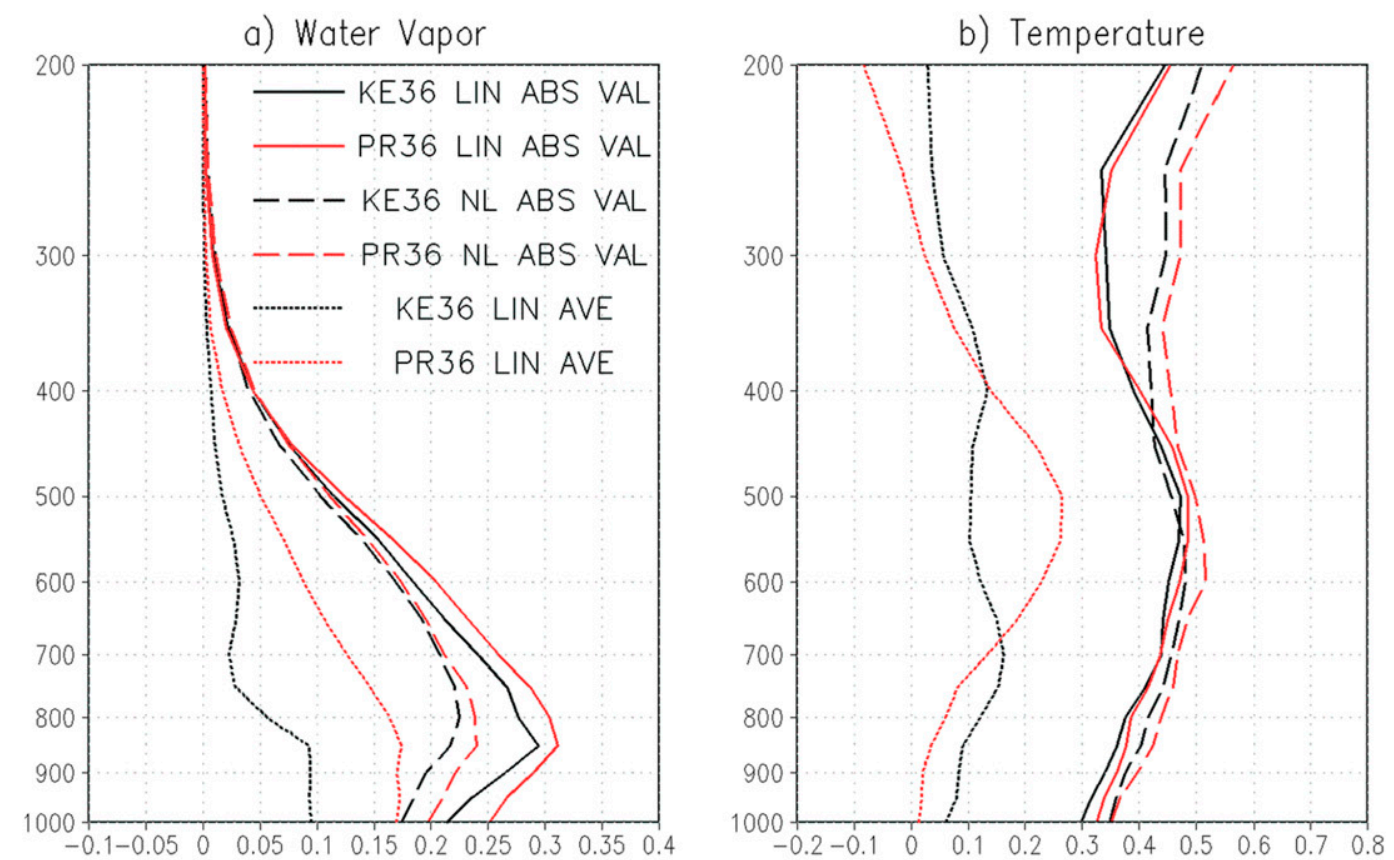

c) Zonal Wind

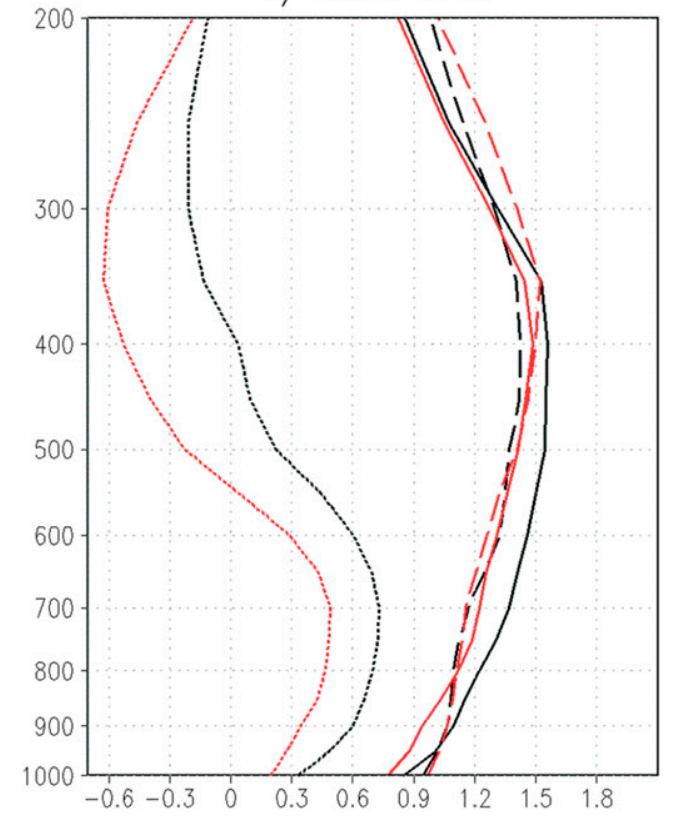

d) Meridional Wind

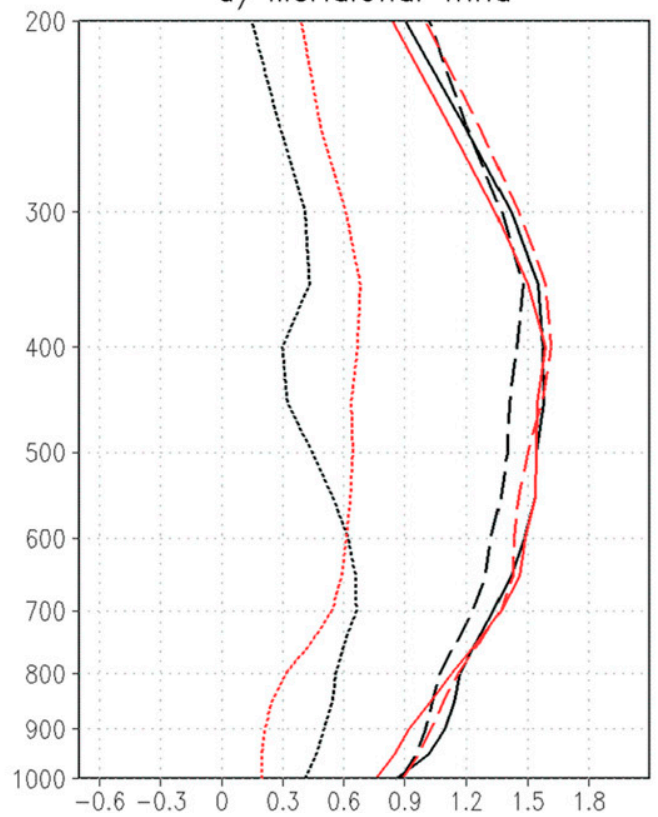

FIG. 13. Vertical profiles of the average absolute value of the final-time optimal perturbation in (a) moisture $\left(\mathrm{g} \mathrm{kg}^{-1}\right)$, (b) temperature $(\mathrm{K})$, (c) zonal wind $\left(\mathrm{m} \mathrm{s}^{-1}\right)$, and (d) meridional wind $\left(\mathrm{m} \mathrm{s}^{-1}\right)$ averaged over the response function box for KE36 (black) and PR36 (red) for the linear-evolved (solid) and nonlinear-evolved (dashed) perturbations as denoted in key in (a). The average final-time linear optimal perturbations are shown with the dotted curves.

onto these fast growing structures will vary from day to day. All these factors will contribute to day-to-day forecast error variability. However, the positive correlation does indicate that there is a general relationship between larger forecast errors and larger initial-time sensitivity, which is also found in Doyle et al. (2019, manuscript submitted to Mon. Wea. Rev.). This is consistent with the results of Reynolds et al. (2005) who find a relationship between adjoint-based singular vector growth and forecast error total energy. 
TABLE 3. Linear and nonlinear perturbation wind speed $\left(\mathrm{m} \mathrm{s}^{-1}\right)$ and precipitation $(\mathrm{mm})$ averaged over the response function domain. Perturbation wind speed is averaged over $1000-850 \mathrm{hPa}$ at final time (either $24 \mathrm{~h}$ or $36 \mathrm{~h}$ ). Precipitation is averaged over the entire optimization period.

\begin{tabular}{lcccc}
\hline \hline & KE24 & PR24 & KE36 & PR36 \\
\hline Linear wind perturbation & 1.15 & 0.55 & 1.36 & 0.66 \\
Nonlinear wind perturbation & 0.95 & 0.47 & 1.06 & 0.54 \\
Linear precipitation perturbation & 0.35 & 0.71 & 0.60 & 1.19 \\
Nonlinear precipitation perturbation & 0.28 & 0.73 & 0.42 & 1.12 \\
\hline
\end{tabular}

Performing the same calculation for precipitation forecasts is problematic, as we expect the fairly coarseresolution simulations to miss many of the finescale orographically forced observed precipitation features. Instead, as a proxy for precipitation forecast uncertainty, we calculate the mean absolute difference between the 30$36-\mathrm{h}$ forecast accumulated precipitation with the $6-12 \mathrm{~h}$ forecast accumulated precipitation from the forecast started the following day (such that the accumulation periods are valid at the same time) for the PR36 cases. This precipitation difference is strongly correlated (0.73) with the domain-averaged vertically integrated moisture sensitivity (Fig. 14b). A similar calculation for PR24 yields a correlation of 0.81 . Similar correlations are found for wind and temperature sensitivity (not shown). As mean absolute differences in precipitation will tend to be larger with larger precipitation amounts, it is of interest to consider these forecast differences relative to the precipitation magnitude. Normalizing the mean absolute difference by the forecasted precipitation amount reduces the correlations to 0.45 and 0.37 for PR24 and PR36, respectively. While the correlations between the normalized precipitation uncertainty and sensitivity are relatively small (though still positive), the strong positive correlations between the full precipitation uncertainty (measured by these forecast differences) and sensitivity magnitude support the relevance of these adjoint calculations for predictability studies and adaptive observing applications.

\section{Summary and conclusions}

We use the COAMPS forecast and adjoint system to examine the sensitivity and related optimal perturbation growth of 24- and 36-h forecasts of low-level KE and precipitation over California to changes in the initial state for the record-breaking precipitation period of 1 January through 20 February 2017. In a time-averaged sense, the most sensitive regions as denoted by the optimal perturbations are very similar for precipitation and low-level wind speed forecasts. The initial moisture and wind sensitivity maxima are found upstream of the RF box, near the latitude of the Eady baroclinicity maximum, and on the northern edge of the maximum IVT. The sensitivity maxima occur between 800 and $500 \mathrm{hPa}$, with a much sharper drop-off with height above that level in moisture than in winds or temperature. Both wind and precipitation forecasts are potentially twice as sensitive to a $1 \mathrm{~g} \mathrm{~kg}^{-1}$ change in moisture as to a $1 \mathrm{~m} \mathrm{~s}^{-1}$ change in zonal or meridional wind. These results suggest that, in a time-averaged sense, the target regions would be the same for forecasting precipitation, especially for orographically dominated precipitation events, as for forecasting low-level wind speeds.

There is considerable variability, however, in the structure and location of the optimal perturbations, on both a day-to-day basis and between the KE and PR RFs. The maximum 24-h sensitivity location can range from north of Hawaii to within the RF box itself. The case study considered here (and others, not shown) indicate that while the general sensitive regions are the same for the KE and PR RFs, the details are different, and they result in substantial differences in perturbation growth. Also, while the correlation between the KE RF and PR RF sensitivity magnitude is positive, there are cases where the KE RF sensitivity is high and the PR RF sensitivity is low, and vice versa. These results indicate that the optimal deployment of adaptive observations, both in terms of timing and location, would be metric dependent.

For the case study considered here, and others (not shown), sensitivity is often in or near an approaching $\mathrm{AR}$ and associated with the inflow and ascent regions of the WCB. The initial moisture sensitivity is not where the moisture is largest, but rather on the edges/boundaries of the ARs in regions where the atmosphere is not saturated. Thus, the optimal perturbations tend to add moisture to the subsaturated regions of the AR, rather than adding moisture to regions that are already saturated and where additional moisture would just rain out. Wind and temperature sensitivities result in PV optimal perturbations that enhance and connect lower- and upper-level high PV features. These findings are consistent with dynamic and thermodynamic theory that highlights the importance of diabatic processes and PV alignment for cyclone intensification (e.g., Kuo et al. 1991; Hoskins and Berrisford 1988; Doyle et al. 2014), and the importance of WCB strength for subsequent cyclone intensification and downstream development (Schäfler and Harnisch 2015; Binder et al. 2016; Grams and Archambault 2016). These AR and WCB regions are also regions of significant analysis uncertainty (e.g., Schäfler et al. 2011; Lavers et al. 2018), which may explain the correlation between sensitivity magnitude and forecast error. While this study has focused on identifying typical sensitivity characteristics and the impact of RF choice, ongoing work is investigating 

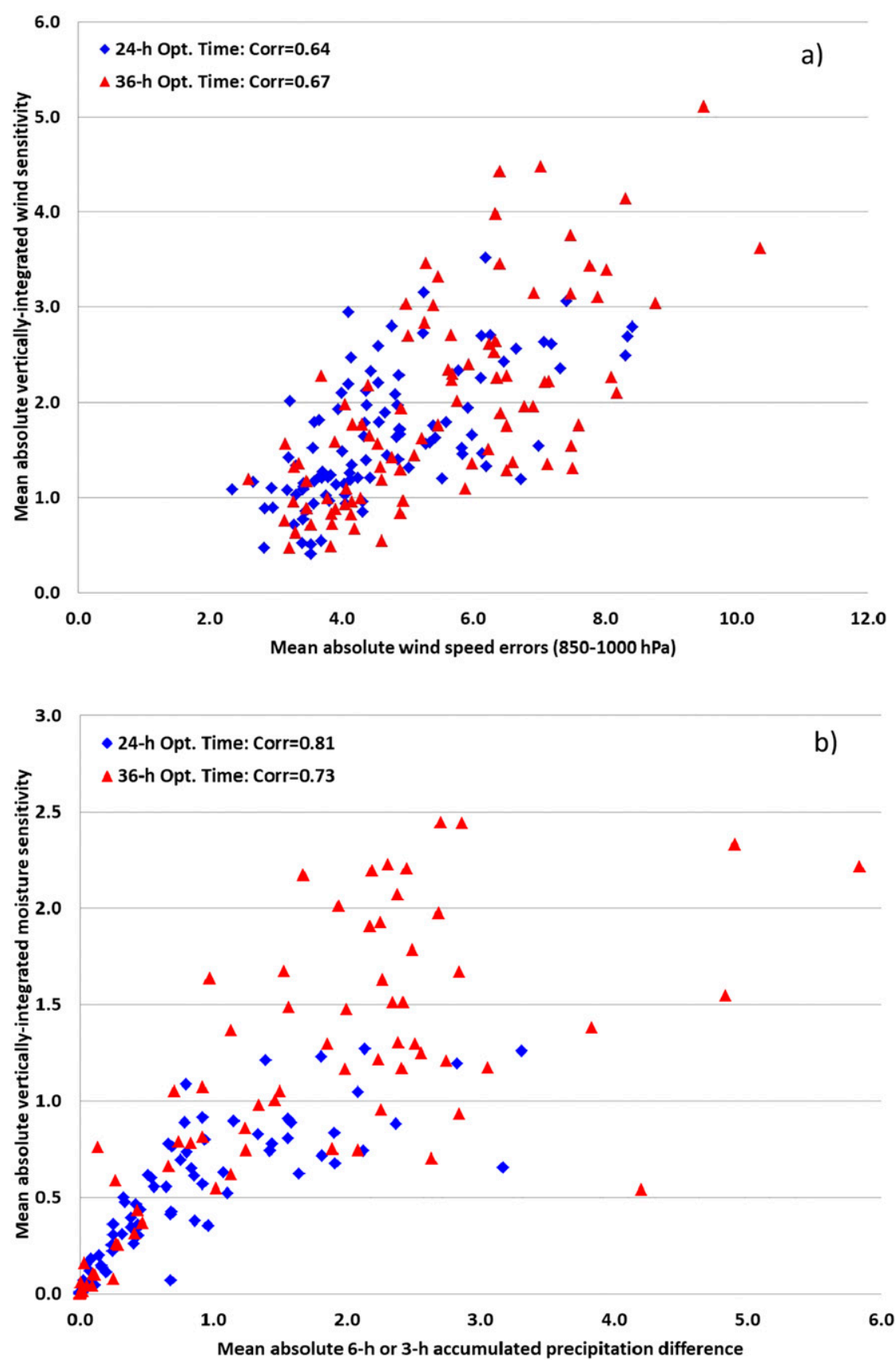

FIG. 14. (a) Final-time mean absolute wind speed errors $\left(\mathrm{m} \mathrm{s}^{-1}\right.$, averaged between 850 and $1000 \mathrm{hPa}$ ) vs the mean absolute vertically integrated KE RF wind sensitivity $\mathrm{m}^{2} \mathrm{~s}^{-2}\left(\mathrm{~m} \mathrm{~s}^{-1}\right)^{-1}$. (b) 21-24 h vs 9-12 h (for 24-h optimization time) and 30-36 h vs 6-12 h (for the 36-h optimization time) accumulated precipitation mean absolute differences $(\mathrm{mm})$ vs the mean absolute vertically

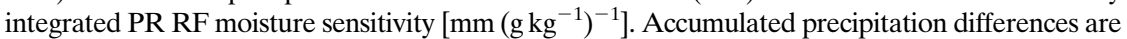
calculated for the same valid times. 24-h optimization times are denoted with blue diamonds and 36-h optimization times are denoted with red triangles. Correlation values are provided in key.

the dynamic and thermodynamic mechanisms enabling rapid perturbation growth.

The adjoint sensitivity technique is constrained by the linearity assumption. While nonlinear perturbation growth is typically smaller than the expected linear perturbation growth, the nonlinear perturbations still grow rapidly, supporting the relevance of this type of analysis to predictability studies. This is particularly 
encouraging as this is a moist adjoint, and nonlinearities are prominent with moist processes. The positive correlation between the magnitude of the sensitivity and forecast wind errors, and forecast precipitation differences, is further support for the relevance to NWP and adaptive observation applications. However, these methods only consider sensitivity of the forecast to changes in the initial state, not changes to the observing system. Adaptive observing methods should ideally take into account the sensitivity of the analysis to the observing system (e.g., Langland and Baker 2004). Current studies are underway examining the impact of AR Reconnaissance dropsonde observations on the representation of ARs in the analyses and on subsequent forecast errors.

While the method employed here quantifies the sensitivity of short-term forecasts to initial perturbations, it does not specifically identify analysis perturbations that would improve the forecast. Klinker et al. (1998) and Rabier et al. (1996) use adjoint techniques to identify initial perturbations constructed to minimize forecast errors, and it would be interesting to employ this technique for AR applications. However, as these perturbations are designed to minimize forecast error that is caused by both model error and initial error, interpretation of these initial perturbations is not straightforward (e.g., Isaksen et al. 2005; Reynolds 2007).

Given the expected sensitivity of forecasted precipitation to model resolution, particularly in areas of complex terrain, it would be interesting to consider the adjoint sensitivity of land-falling ARS at convective-permitting resolutions in conjunction with an observation impact study using observations from a field project such as AR Recon or NAWDEX. A study like this would address several recommendations in the targeted observation review paper by Majumdar (2016) such as improving understanding of socioeconomic impact of targeted observations, exploring the potential for use with convective-scale models, and assessing the role of DA methodology.

Acknowledgments. C. A. R. and J. D. D. gratefully acknowledge the support of the Chief of Naval Research through the NRL Base Program, PE 0601153N. Computational resources were provided by the Navy DSRC in Stennis, Mississippi. The authors thank the three anonymous reviewers for their insightful comments that helped to improve the manuscript.

\section{REFERENCES}

Amerault, C., X. Zou, and J. D. Doyle, 2008: Tests of an adjoint mesoscale model with explicit moist physics on the cloud scale. Mon. Wea. Rev., 136, 2120-2132, https://doi.org/10.1175/2007MWR2259.1.

Ancell, B. C., and C. F. Mass, 2006: Structure, growth rates, and tangent linear accuracy of adjoint sensitivities with respect to horizontal and vertical resolution. Mon. Wea. Rev., 134, 29712988, https://doi.org/10.1175/MWR3227.1.

— A. Aogusz, M. J. Lauridsen, and C. J. Nauert, 2018: Seeding chaos: The dire consequences of numerical noise in NWP perturbation experiments. Bull. Amer. Meteor. Soc., 99, 615628, https://doi.org/10.1175/BAMS-D-17-0129.1.

Badger, J., and B. J. Hoskins, 2001: Simple initial value problems and mechanisms for baroclinic growth. J. Atmos. Sci., 58, 38-49, https://doi.org/10.1175/1520-0469(2001)058<0038: SIVPAM $>2.0 . \mathrm{CO} ; 2$.

Bednarczyk, C. N., and B. C. Ancell, 2015: Ensemble sensitivity analysis applied to a southern plains convective event. Mon. Wea. Rev., 143, 230-249, https://doi.org/10.1175/MWR-D-13-00321.1.

Binder, H., M. Boettcher, H. Joos, and H. Wernli, 2016: The role of warm conveyor belts for the intensification of extratropical cyclones in Northern Hemisphere winter. J. Atmos. Sci., $\mathbf{7 3}$, 3997-4020, https://doi.org/10.1175/JAS-D-15-0302.1.

Buizza, R., and T. N. Palmer, 1995: The singular-vector structure of the atmospheric global circulation. J. Atmos. Sci., 52, 1434-1456, https://doi.org/10.1175/1520-0469(1995)052<1434:TSVSOT>2.0.CO;2.

Carlson, T. N., 1980: Airflow through midlatitude cyclones and the comma cloud pattern. Mon. Wea. Rev., 108, 1498-1509, https:// doi.org/10.1175/1520-0493(1980)108<1498:ATMCAT>2.0.CO;2.

Chagnon, J. M., S. L. Gray, and J. Methven, 2013: Diabatic processes modifying potential vorticity in a North Atlantic cyclone. Quart. J. Roy. Meteor. Soc., 139, 1270-1282, https://doi.org/ 10.1002/qj.2037.

Chang, E. K. M., M. Zheng, and K. Raeder, 2013: Medium-range ensemble sensitivity analysis of two extreme Pacific extratropical cyclones. Mon. Wea. Rev., 141, 211-231, https://doi.org/ 10.1175/MWR-D-11-00304.1.

Cordeira, J. M., F. M. Ralph, and B. J. Moore, 2013: The development and evolution of two atmospheric rivers in proximity to western North Pacific tropical cyclones in October 2010. Mon. Wea. Rev., 141, 4234-4255, https://doi.org/10.1175/MWR-D-13-00019.1.

DeFlorio, M. J., D. E. Waliser, B. Guan, D. A. Lavers, F. M. Ralph, and F. Vitart, 2018: Global assessment of atmospheric river prediction skill. J. Hydrometeor., 19, 409-426, https://doi.org/ 10.1175/JHM-D-17-0135.1.

Dettinger, M. D., F. M. Ralph, T. Das, P. J. Neiman, and D. Cayan, 2011: Atmospheric rivers, floods, and the water resources of California. Water, 3, 445-478, https://doi.org/10.3390/w3020445.

Doyle, J. D., C. A. Reynolds, and C. Amerault, 2011: Diagnosing tropical cyclone sensitivity. Comput. Sci. Eng., 13, 31-39, https://doi.org/10.1109/MCSE.2010.146.

,,--- , and J. Moskaitis, 2012: Adjoint sensitivity and predictability of tropical cyclogenesis. J. Atmos. Sci., 69, 35353557, https://doi.org/10.1175/JAS-D-12-0110.1.

- C. Amerault, C. A. Reynolds, and P. A. Reinecke, 2014: Initial condition sensitivity and predictability of a severe extratropical cyclone using a moist adjoint. Mon. Wea. Rev., 142, 320-342, https://doi.org/10.1175/MWR-D-13-00201.1.

Errico, R. M., 1997: What is an adjoint model? Bull. Amer. Meteor. Soc., 78, 2577-2591, https://doi.org/10.1175/1520-0477(1997) $078<2577$ :WIAAM $>2.0$.CO;2.

— of the linearization of a mesoscale model with moist physics. Quart. J. Roy. Meteor. Soc., 125, 169-195, https://doi.org/10.1002/ qj. 49712555310.

,,- , and L. Fillion, 2003: Examination of the sensitivity of forecast precipitation rates to possible perturbations of initial conditions. Tellus, 55A, 88-105, https://doi.org/10.3402/ tellusa.v55i1.12083. 
Farrell, B. F., 1982: The initial growth of disturbances in a baroclinic flow. J. Atmos. Sci., 39, 1663-1686, https://doi.org/10.1175/15200469(1982)039<1663:TIGODI > 2.0.CO;2.

_ 1989: Optimal excitation of baroclinic waves. J. Atmos. Sci., 46, 1193-1206, https://doi.org/10.1175/1520-0469(1989)046<1193: OEOBW $>2.0 . \mathrm{CO} ; 2$.

Fritts, D., and Coauthors, 2016: The Deep Propagating Gravity Wave Experiment (DEEPWAVE): An airborne and groundbased exploration of gravity wave propagation and effects from their sources throughout the lower and middle atmosphere. Bull. Amer. Meteor. Soc., 97, 425-453, https://doi.org/ 10.1175/BAMS-D-14-00269.1.

Gelaro, R., C. A. Reynolds, R. H. Langland, and G. D. Rohaly, 2000: A predictability study using geostationary satellite wind observations during NORPEX. Mon. Wea. Rev., 128, 3789-3807, https://doi.org/10.1175/1520-0493(2001)129<3789: APSUGS $>2.0 . \mathrm{CO} ; 2$.

Gimeno, L., R. Nieto, M. Vazquez, and D. A. Lavers, 2014: Atmospheric rivers: A mini-review. Front. Earth Sci., 2 (2), https://doi.org/10.3389/feart.2014.00002.

Grams, C. M., and H. M. Archambault, 2016: The key role of diabatic outflow in amplifying the midlatitude flow: A representative case study of weather systems surrounding western North Pacific extratropical transition. Mon. Wea. Rev., 144, 3847-3869, https://doi.org/10.1175/MWR-D-15-0419.1.

Hecht, C. W., and J. M. Cordeira, 2017: Characterizing the influence of atmospheric river orientation and intensity on precipitation distributions over north coastal California. Geophys. Res. Lett., 44, 9048-9058, https://doi.org/10.1002/ 2017GL074179.

Hodur, R. M., 1997: The Naval Research Laboratory's Coupled Ocean/Atmospheric Mesoscale Prediction System (COAMPS). Mon. Wea. Rev., 125, 1414-1430, https://doi.org/10.1175/15200493(1997)125<1414:TNRLSC $>2.0$.CO;2.

Hoskins, B. J., and P. Berrisford, 1988: A potential vorticity perspective of the storm of 15-16 October 1987. Weather, 43, 122129, https://doi.org/10.1002/j.1477-8696.1988.tb03890.x.

_ , and M. A. Pedder, 1980: The diagnosis of middle latitude synoptic development. Quart. J. Roy. Meteor. Soc., 106, 707719, https://doi.org/10.1002/qj.49710645004.

— , and P. J. Valdes, 1990: On the existence of storm-tracks. J. Atmos. Sci., 47, 1854-1864, https://doi.org/10.1175/15200469(1990)047<1854:OTEOST>2.0.CO;2.

Isaksen, L., M. Fisher, E. Andersson, and J. Barkmeijer, 2005: The structure and realism of sensitivity perturbations and their interpretation as 'key analysis errors.' Quart. J. Roy. Meteor. Soc., 131, 3053-3078, https://doi.org/10.1256/qj.04.99.

Jung, B.-J., H. M. Kim, T. Auligné, X. Zhang, X. Zhang, and X.-Y. Huang, 2013: Adjoint-derived observation impact using WRF in the western North Pacific. Mon. Wea. Rev., 141, 4080-4097, https://doi.org/10.1175/MWR-D-12-00197.1.

Kim, H. M., and B.-J. Jung, 2009: Singular vector structure and evolution of a recurving tropical cyclone. Mon. Wea. Rev., 137, 505-524, https://doi.org/10.1175/2008MWR2643.1.

Kleist, D. T., and M. C. Morgan, 2005: Interpretation of the structure and evolution of adjoint-derived forecast sensitivity gradients. Mon. Wea. Rev., 133, 466-484, https://doi.org/ 10.1175/MWR-2865.1.

Klinker, E., F. Rabier, and R. Gelaro, 1998: Estimation of key analysis errors using the adjoint technique. Quart. J. Roy. Meteor. Soc., 124, 1909-1933, https://doi.org/10.1002/qj.49712455007.

Kuo, Y.-H., M. A. Shapiro, and E. G. Donall, 1991: The interaction between baroclinic and diabatic processes in a numerical simulation of a rapidly intensifying extratropical marine cyclone. Mon. Wea. Rev., 119, 368-384, https://doi.org/10.1175/ 1520-0493(1991)119<0368:TIBBAD > 2.0.CO;2.

Lackmann, G. M., 2002: Cold-frontal potential vorticity maxima, the low-level jet, and moisture transport in extratropical cyclones. Mon. Wea. Rev., 130, 59-74, https://doi.org/10.1175/ 1520-0493(2002)130<0059:CFPVMT $>2.0 . C O ; 2$.

Lang, S. T. K., S. C. Jones, M. Leutbecher, M. S. Peng, and C. A. Reynolds, 2012: Sensitivity, structure, and dynamics of singular vectors associated with Hurricane Helene (2006). J. Atmos. Sci., 69, 675-694, https://doi.org/10.1175/JAS-D11-048.1.

Langland, R. H., and N. L. Baker, 2004: Estimation of observation impact using the NRL atmospheric variational data assimilation adjoint system. Tellus, 56A, 189-201, https://doi.org/ 10.1111/j.1600-0870.2004.00056.x.

_ R. L. Elsberry, and R. M. Errico, 1995: Evaluation of physical processes in an idealized extratropical cyclone using adjoint sensitivity. Quart. J. Roy. Meteor. Soc., 121, 1349-1386, https:// doi.org/10.1002/qj.49712152608.

Lavers, D. A., and G. Villarini, 2013: The nexus between atmospheric rivers and extreme precipitation across Europe. Geophys. Res. Lett., 40, 3259-3264, https://doi.org/10.1002/ grl.50636.

R. P. Allan, E. F. Wood, G. Villarini, D. J. Brayshaw, and A. J. Wade, 2011: Winter floods in Britain are connected to atmospheric rivers. Geophys. Res. Lett., 38, L23803, https:// doi.org/10.1029/2011GL049783.

—, D. E. Waliser, F. M. Ralph, and M. D. Dettinger, 2016a: Predictability of horizontal water vapor transport relative to precipitation: Enhancing situational awareness for forecasting western U.S. extreme precipitation and flooding. Geophys. Res. Lett., 43, 2275-2282, https://doi.org/ 10.1002/2016GL067765.

F. Pappenberger, D. S. Richardson, and E. Zsoter, 2016b: ECMWF Extreme Forecast Index for water vapor transport: A forecast tool for atmospheric rivers and extreme precipitation. Geophys. Res. Lett., 43, 11 852-11 858, https://doi.org/ 10.1002/2016GL071320.

—, M. J. Rodwell, D. S. Richardson, F. M. Ralph, J. D. Doyle, C. A. Reynolds, V. Tallapragada, and F. Pappenberger, 2018: The gauging and modeling of rivers in the sky. Geophys. Res. Lett., 45, 7828-7834, https://doi.org/10.1029/2018GL079019.

Louis, J. F., M. Tiedtke, and J. F. Geleyn, 1982: A short history of the operational PBL-parameterization of ECMWF. Proc. 1981 ECMWF Workshop on Planetary Boundary Layer Parameterization, Shinfield Park, Reading, United Kingdom, ECMWF, 59-79 .

Lynch, S., and R. Schumacher, 2014: Ensemble-based analysis of the May 2010 extreme rainfall in Tennessee and Kentucky. Mon. Wea. Rev., 142, 222-239, https://doi.org/10.1175/MWRD-13-00020.1.

Mahfouf, J.-F., and B. Bilodeau, 2007: Adjoint sensitivity of surface precipitation to initial conditions. Mon. Wea. Rev., 135, 2879_ 2896, https://doi.org/10.1175/MWR3439.1.

Majumdar, S., 2016: A review of targeted observations. Bull. Amer. Meteor. Soc., 97, 2287-2303, https://doi.org/10.1175/ BAMS-D-14-00259.1.

Molinari, J., 1985: General form of Kuo's cumulus parameterization. Mon. Wea. Rev., 113, 1411-1416, https://doi.org/10.1175/15200493(1985)113<1411:AGFOKC>2.0.CO;2.

Neiman, P. J., L. J. Schick, F. M. Ralph, M. Hughes, and G. A. Wick, 2011: Flooding in western Washington: The connection 
to atmospheric rivers. J. Hydrometeor., 12, 1337-1358, https:// doi.org/10.1175/2011JHM1358.1.

Oortwijn, J., and J. Barkmeijer, 1995: Perturbations that optimally trigger weather regimes. J. Atmos. Sci., 52, 39323944, https://doi.org/10.1175/1520-0469(1995)052<3932: PTOTWR $>2.0$.CO;2.

Orr, W. McF., 1907: Stability or instability of the steady motions of a perfect liquid. Proc. Roy. Irish Acad., 21, 9-69.

Palmer, T. N., R. Gelaro, J. Barkmeijer, and R. Buizza, 1998: Singular vectors, metrics and adaptive observations. J. Atmos. Sci., 55, 633-653, https://doi.org/10.1175/1520-0469(1998) 055<0633:SVMAAO $>2.0 . \mathrm{CO} ; 2$.

Peng, M. S., and C. A. Reynolds, 2006: Sensitivity of tropical cyclone forecasts as revealed by singular vectors. J. Atmos. Sci., 63, 2508-2528, https://doi.org/10.1175/JAS3777.1.

Rabier, F., E. Klinker, P. Courtier, and A. Hollingsworth, 1996: Sensitivity of forecast errors to initial conditions. Quart. J. Roy. Meteor. Soc., 122, 121-150, https://doi.org/10.1002/ qj.49712252906.

Ralph, F. M., and Coauthors, 2017: Dropsonde observations of total integrated water vapor transport within North Pacific atmospheric rivers. J. Hydrometeor., 18, 2577-2596, https:// doi.org/10.1175/JHM-D-17-0036.1.

_- 2018: Atmospheric river reconnaissance-2018 is underway. Center for Western Weather and Water Extremes, accessed 21 August 2018, http://cw3e.ucsd.edu/atmospheric-riverreconnaissance-2018-underway/.

_ aircraft observations of atmospheric rivers over the eastern North Pacific Ocean during the El Niño winter of 1997/98. Mon. Wea. Rev., 132, 1721-1745, https://doi.org/10.1175/15200493(2004)132<1721:SACAOO > 2.0.CO;2.

,-- , and R. Rotunno, 2005: Dropsonde observations in low-level jets over the northeastern Pacific Ocean from CALJET-1998 and PACJET-2001: Mean vertical-profile and atmospheric-river characteristics. Mon. Wea. Rev., 133, 889-910, https://doi.org/10.1175/MWR2896.1.

,-- G. A. Wick, S. I. Gutman, M. D. Dettinger, D. R. Cayan, and A. B. White, 2006: Flooding on California's Russian River: Role of atmospheric rivers. Geophys. Res. Lett., 33, L13801, https://doi.org/10.1029/2006GL026689.

_ - and Coauthors, 2016: CalWater field studies designed to quantify the roles of atmospheric rivers and aerosols in modulating U.S. West Coast precipitation in a changing climate. Bull. Amer. Meteor. Soc., 97, 1209-1228, https://doi.org/ 10.1175/BAMS-D-14-00043.1.

—, M. D. Dettinger, M. M. Cairns, T. J. Galarneau, and J. Eylander, 2018: Defining "atmospheric river": How the Glossary of Meteorology helped resolve a debate. Bull. Amer. Meteor. Soc., 99, 837-839, https://doi.org/10.1175/BAMS-D17-0157.1.

Ramos, A. M., R. M. Trigo, M. L. R. Liberato, and T. Ricardo, 2015: Daily precipitation extreme events in the Iberian Peninsula and its association with atmospheric rivers. J. Hydrometeor., 16, 579-597, https://doi.org/10.1175/JHM-D-14-0103.1.

Reynolds, C. A., 2007: The impact of nonlinearities and model error on pseudo-inverse calculations. Physica D, 230, 159-171.

— based perturbations. Quart. J. Roy. Meteor. Soc., 129, 30593078, https://doi.org/10.1256/qj.02.193.

_ , R. Gelaro, and J. Doyle, 2001: Relationship between singular vectors and transient features in the background flow. Quart.
J. Roy. Meteor. Soc., 127, 1731-1760, https://doi.org/10.1002/ qj.49712757514.

,-- _ and T. E. Rosmond, 2005: A comparison of variance and total-energy singular-vectors. Quart. J. Roy. Meteor. Soc., 131, 1955-1973, https://doi.org/10.1256/qj.04.132.

— J. J. Doyle, R. M. Hodur, and H. Jin, 2010: Naval Research Laboratory multi-scale targeting guidance for T-PARC and TCS-08. Wea. Forecasting, 25, 526-544, https://doi.org/ 10.1175/2009WAF2222292.1.

- - - , and X. Hong, 2016: Examining tropical cycloneKelvin wave interactions using adjoint diagnostics. Mon. Wea. Rev., 144, 4421-4439, https://doi.org/10.1175/MWR-D16-0174.1.

Rutledge, S. A., and P. V. Hobbs, 1983: The mesoscale and microscale structure of organization of clouds and precipitation in midlatitude cyclones. VIII: A model for the "seederfeeder" process in warm frontal rainbands. J. Atmos. Sci., 40 , 1185-1206, https://doi.org/10.1175/1520-0469(1983)040<1185: TMAMSA $>2.0 . \mathrm{CO} ; 2$.

Schäfler, A., and F. Harnisch, 2015: Impact of the inflow moisture on the evolution of a warm conveyor belt. Quart. J. Roy. Meteor. Soc., 141, 299-310, https://doi.org/10.1002/ qj. 2360 .

_ A. Dornbrack, H. Wernli, C. Kiemle, and S. Pfahl, 2011: Airborne lidar observations in the inflow region of a warm conveyor belt. Quart. J. Roy. Meteor. Soc., 137, 1257-1272, https://doi.org/10.1002/qj.827.

_- , and Coauthors, 2018: The North Atlantic Waveguide and Downstream Impact Experiment. Bull. Amer. Meteor. Soc., 99, 1607-1637, https://doi.org/10.1175/BAMS-D-170003.1.

Schumacher, R., 2011: Ensemble-based analysis of factors leading to the development of a multiday warm-season heavy rain event. Mon. Wea. Rev., 139, 3016-3035, https://doi.org/ 10.1175/MWR-D-10-05022.1.

Smith, G. C., and Coauthors, 2018: Impact of coupling with an ice-ocean model on global medium-range NWP forecast skill. Mon. Wea. Rev., 146, 1157-1180, https://doi.org/10.1175/ MWR-D-17-0157.1.

Smith, N. H., and B. C. Ancell, 2017: Ensemble sensitivity analysis of wind ramp events with applications to observation targeting. Mon. Wea. Rev., 145, 2505-2522, https://doi.org/10.1175/ MWR-D-16-0306.1.

Stappers, R., and J. Barkmeijer, 2011: Properties of singular vectors using convective available potential energy as a final time norm. Tellus, 63A, 373-384, https://doi.org/10.1111/ j.1600-0870.2010.00501.x.

Torn, R. D., and G. J. Hakim, 2008: Ensemble-based sensitivity analysis. Mon. Wea. Rev., 136, 663-677, https://doi.org/10.1175/ 2007MWR2132.1.

$\longrightarrow$, and - 2009: Initial condition sensitivity of western Pacific extratropical transitions determined using ensemble-based sensitivity analysis. Mon. Wea. Rev., 137, 3388-3406, https:// doi.org/10.1175/2009MWR2879.1.

Waliser, D., and B. Guan, 2017: Extreme winds and precipitation during landfall of atmospheric rivers. Nat. Geosci., 10, 179183, https://doi.org/10.1038/ngeo2894.

Wernli, H., 1997: A Lagrangian-based analysis of extratropical cyclones. II. A detailed case-study. Quart. J. Roy. Meteor. Soc., 123, 467-489, https://doi.org/10.1002/qj.49712353811.

Yu, H., and Z. Meng, 2016: Key synoptic-scale features influencing the high-impact heavy rainfall in Beijing, China, on 21 July 2012. Tellus, 68A, 31045, https://doi.org/10.3402/tellusa.v68.31045. 
Zhang, M., and Z. Meng, 2018: Impact of synoptic-scale factors on rainfall forecast in different stages of a persistent heavy rainfall event in South China. J. Geophys. Res. Atmos., 123, 35743593, https://doi.org/10.1002/2017JD028155.

Zheng, M., E. K. M. Chang, and B. A. Colle, 2013: Ensemble sensitivity tools for assessing extratropical cyclone intensity and track predictability. Wea. Forecasting, 28, 1133-1156, https://doi.org/10.1175/WAF-D-12-00132.1.
Zhou, F., and X. Cui, 2015: The adjoint sensitivity of heavy rainfall to initial conditions in debris flow areas in China. Atmos. Sci. Lett., 16, 485-491, https://doi.org/ 10.1002/asl.586.

Zhu, Y., and R. E. Newell, 1998: A proposed algorithm for moisture fluxes from atmospheric rivers. Mon. Wea. Rev., 126, 725-735, https://doi.org/10.1175/1520-0493(1998) $126<0725$ :APAFMF $>2.0 . \mathrm{CO} ; 2$. 